\title{
The Effect of Injection Parameters and Boost Pressure on Diesel-Propane Dual Fuel Low Temperature Combustion in a Single-Cylinder Research Engine
}

\author{
Sundar Rajan Krishnan ${ }^{1}$, Kalyan Kumar Srinivasan, Mostafa Shameem Raihan ${ }^{2}$ \\ Department of Mechanical Engineering, Mississippi State University, \\ Mississippi State, MS 39762, USA
}

\begin{abstract}
Diesel-ignited propane dual fuel low temperature combustion was characterized in a singlecylinder research engine (SCRE) at constant values of indicated mean effective pressure (IMEP of 5.1 bar), engine speed $(1500 \mathrm{rpm})$, and propane energy substitution (PES $=80 \%)$. The effects of three important engine parameters (start of injection (SOI) of diesel fuel, common-rail pressure ( $\left.\mathrm{P}_{\text {rail }}\right)$ for diesel injection, and boost pressure $\left.\left(\mathrm{P}_{\mathrm{in}}\right)\right)$ on engine performance, combustion, and emissions were examined. As SOI was advanced from 355 absolute crank angle degrees (CAD) (or $5^{\circ} \mathrm{BTDC}$ ) to $280 \mathrm{CAD}$ for constant $\mathrm{P}_{\text {rail }}=500 \mathrm{bar}$ and $\mathrm{P}_{\mathrm{in}}=1.5 \mathrm{bar}$, the apparent heat release rate (AHRR) profiles changed from a two-stage, "diesel-like" combustion process to a smooth, "Gaussian-like," single-stage combustion process, that was representative of more homogeneous combustion. In addition, with SOI advancement, the combustion phasing (CA50) was initially advanced but eventually occurred later for very early SOIs. Indicated-specific emissions of oxides of nitrogen (ISNOx) were reduced to about $0.12 \mathrm{~g} / \mathrm{kWh}$ for SOIs advanced beyond $310 \mathrm{CAD}$ while maintaining high indicated fuel conversion efficiencies (IFCEs). While smoke emissions were below 0.1 FSN for all conditions tested in this study, indicated-specific hydrocarbon (ISHC) and
\end{abstract}

\footnotetext{
${ }^{1}$ Corresponding Author; E-mail: krishnan@me.msstate.edu, T: +1-662-325-1544, F: +1-662-325-7223, Mechanical Engineering Department, Mississippi State University, Mississippi State, MS 39762

${ }^{2}$ Current Affiliation: Cummins, Inc.
} 
carbon monoxide (ISCO) emissions were high at both very early and very late SOIs. Efficiencyemissions tradeoffs indicated an "optimal" SOI of 310 CAD under these conditions, which was chosen for further studies at different $\mathrm{P}_{\text {rail }}$ and $\mathrm{P}_{\text {in }}$. Decreasing $\mathrm{P}_{\text {rail }}$ from 1300 bar to 200 bar at $\mathrm{P}_{\text {in }}$ $=1.5$ bar led to a steep increase in ISNOx emissions for $\mathrm{P}_{\text {rail }}$ below 400 bar; however IFCE and smoke were relatively invariant with $\mathrm{P}_{\text {rail. }}$. Boost pressure effects were then quantified at $\mathrm{P}_{\text {rail }}=$ 500 bar. As $\mathrm{P}_{\text {in }}$ was increased from 1.1 bar to 1.8 bar, the ignition delay decreased and the AHRR profiles continued to exhibit single-stage combustion, albeit with different rates and peak magnitudes. Moreover, with increasing $\mathrm{P}_{\text {in }}$, the IFCE and ISCO increased while ISNOx and ISHC decreased slightly. Finally, the impact of SOI, $\mathrm{P}_{\text {rail, }}$ and $\mathrm{P}_{\text {in }}$ variations on engine stability (i.e., COV of IMEP), maximum pressure rise rates (MPRRs), and combustion duration were also characterized.

Keywords. dual fuel; low temperature combustion; injection timing; RCCI, propane; $\mathrm{NO}_{\mathrm{x}}$ emissions

\section{ABBREVIATIONS}

AHRR Apparent Heat Release Rate, J/deg

BDC Bottom Dead Center

BMEP Brake Mean Effective Pressure, bar

BTDC Before Top Dead Center

CA10-90 Crank angle degrees between the locations of $10 \%$ and $90 \%$ cumulative heat release, $\mathrm{CAD}$

CA5 Crank angle at which $5 \%$ of cumulative heat release occurs, CAD 
CA50 Crank angle at which $50 \%$ of cumulative heat release occurs, CAD

CAD Crank Angle Degrees

$\mathrm{CO} \quad$ Carbon monoxide, $\mathrm{g} / \mathrm{kWh}$

COV Coefficient of Variation, $\%$

EGR Exhaust Gas Recirculation

EOI End of Injection of Diesel, CAD

FSN Filter Smoke Number

HC Unburned hydrocarbon, $\mathrm{g} / \mathrm{kWh}$

HCCI Homogeneous Charge Compression Ignition

ID Ignition Delay, CAD

IFCE Indicated Fuel Conversion Efficiency, \%

IMEP Indicated Mean Effective Pressure, bar

LHV Lower Heating Value, MJ/kg

LTC Low temperature combustion

MPRR Maximum Pressure Rise Rate, bar/CAD

NOx Oxides of nitrogen, $\mathrm{g} / \mathrm{kWh}$

PES Percent Energy Substitution, \%

$\mathrm{P}_{\text {in }} \quad$ Intake manifold (boost) pressure, bar

$\mathrm{P}_{\text {rail }} \quad$ Rail pressure, bar

RCCI Reactivity Controlled Compression Ignition

SOC Start of Combustion, CAD

SOI Start of Injection of Diesel, CAD

TDC Top Dead Center 
Combustion Efficiency, \% 


\section{INTRODUCTION}

Recent interest in improving the fuel conversion efficiency (FCE) and reducing the carbon dioxide $\left(\mathrm{CO}_{2}\right)$ emissions from internal combustion engines has refocused attention on advanced combustion strategies and alternative fuels. Advanced low temperature combustion (LTC) strategies have been proposed for compression ignition engines to simultaneously reduce engineout emissions of oxides of nitrogen (NOx) and soot. It is well known that NOx formation through the thermal mechanism increases exponentially when local in-cylinder temperatures exceed a certain threshold value ( $1900 \mathrm{~K})$; LTC strategies reduce NOx emissions by decreasing local incylinder temperatures below this threshold. To reduce soot formation, locally fuel-rich regions must be avoided. This is accomplished in most partially premixed LTC strategies by improving fuel-air mixing rates and/or by increasing the time available for mixing (i.e., residence time) before the onset of combustion. Consequently, a primary goal of many LTC strategies is to achieve some separation between the fuel injection and combustion events by increasing ignition delay, which increases the residence time and affords better fuel-air mixing, thereby reducing local equivalence ratios below the soot formation threshold and local temperatures below the NOx formation threshold. Some LTC strategies include, for example, homogeneous charge compression ignition (HCCI) [1], partially premixed combustion [2,3], gasoline compression ignition combustion [4,5], as well as various dual fuel LTC strategies [6-10]. Each of these strategies has its own set of advantages and challenges but generally most LTC strategies are accompanied by high unburned hydrocarbon (HC) and carbon monoxide (CO) emissions.

Dual fuel engines have been pursued for several decades [11-22], particularly with natural gas as the primary fuel, with the main intention of improving exhaust emissions while maintaining diesel-like FCEs. In dual fuel combustion, an easily auto-ignitable high-cetane fuel (e.g., diesel) 
is used to ignite an autoignition-resistant low-cetane primary fuel (e.g., methane). Before discussing the scope of the present work and how it fits with the existing literature, it is perhaps useful to examine well-established trends for performance and emissions in dual fuel combustion. For example, it is well known that both NOx and soot emissions in dual fuel combustion decrease with increasing percent energy substitution (PES) of the primary fuel [23-26]. According to Dec's conceptual model of diesel combustion [27], NOx is formed in the high temperature regions near the periphery of the diesel jet where the diffusion flame exists while soot is formed in fuel-rich areas, especially in the head vortex region. In dual fuel combustion, since the primary fuel-air mixture is lean and nearly homogeneous, it engenders very little NOx or soot formation; therefore, both NOx and soot are formed within the diesel jet. Consequently, as the size of the diesel jet decreases with increasing PES of the primary fuel, both NOx and soot decrease but usually at the expense of higher $\mathrm{HC}$ and $\mathrm{CO}$ emissions, especially at low loads.

Of particular interest to the present work are dual fuel LTC strategies that target high FCEs and low engine-out NOx and soot emissions. Reviewing past literature, it is evident that dual fuel LTC is a logical outgrowth from conventional dual fuel combustion with emphasis on achieving LTC using modern engine control hardware and software. With precise gaseous fuel injection, electronic control over diesel injection timing and quantity, boost pressure, exhaust gas recirculation (EGR), etc., conventional dual fuel combustion has been extended to LTC regimes $[6-7,28-32]$. Since the overall reactivity of the fuels is "stratified" between the high-cetane and low-cetane fuels within the combustion chamber, dual fuel LTC is also known more recently as reactivity controlled compression ignition (RCCI) combustion [33].

Dual fuel LTC has been demonstrated with diesel as the high-cetane fuel and a variety of primary, low-cetane fuels such as methane or natural gas [34-35], gasoline [10,33,36], ethanol 
[37], etc. Among gaseous primary fuels for dual fuel LTC, methane (or natural gas) has been investigated quite extensively. On the other hand, while conventional diesel-ignited propane dual fuel combustion has been studied by several researchers [38-43], very few studies have focused on propane as the primary fuel for dual fuel LTC (e.g., $[44,45])$. The present effort is an attempt

to fill this gap. Building on previous research efforts on dual fuel LTC at Mississippi State University (MSU) [34-36, 44-45], this paper presents experimental results for diesel-ignited propane dual fuel LTC on a single-cylinder research engine (SCRE). Considering the wellestablished infrastructure for propane production and distribution within the United States, it is attractive as the primary fuel for dual fuel LTC. Moreover, propane has a higher lower heating value (LHV) compared to diesel, is easier to store (in the liquefied phase) compared to methane (natural gas), and exhibits a relatively high resistance to knock (RON 112, MON 97). Consequently, it is well-suited as the primary fuel for dual fuel LTC.

\section{OBJECTIVE}

The objective of the present work is to implement diesel-ignited propane dual fuel LTC on the MSU SCRE and assess the effects of start of (diesel) injection (SOI), diesel common-rail pressure $\left(\mathrm{P}_{\text {rail }}\right)$ and intake boost pressure $\left(\mathrm{P}_{\text {in }}\right)$ on engine performance, combustion, and exhaust emissions.

\section{EXPERIMENTAL SETUP}

The experiments were performed on the SCRE, whose details are provided in Table 1. As shown in the schematic of the experimental setup (Fig. 1), the engine was coupled to a $250 \mathrm{HP}$ 
Dyne Systems AC regenerative dynamometer, which was controlled by an Inter-Lock V controller that also provided torque and speed measurements.

\subsection{Data Acquisition}

Both crank-resolved data and steady-state data were acquired in the experiments discussed in this paper. Intake, exhaust, coolant, and oil temperatures were measured using Omega Type-K thermocouples. Gaseous and exhaust emissions were measured downstream of the exhaust manifold using an emissions sampling trolley and an integrated emissions bench (EGAS 2M) manufactured by Altech Environment S.A. The EGAS $2 \mathrm{M}$ bench measured total hydrocarbons (THC) with a heated flame ionization detector, NOx emissions with a chemiluminescence detector, carbon dioxide $\left(\mathrm{CO}_{2}\right)$ and carbon monoxide $(\mathrm{CO})$ emissions with a non-dispersive infrared analyzer, and oxygen $(\mathrm{O} 2)$ with a paramagnetic detector. Smoke was measured in filter smoke number (FSN) units using an AVL 415S variable sampling smoke meter.

Mass flow rates of diesel and propane were measured with Micro Motion (Model CMF025M319N2BAEZZZ) coriolis mass flow meters with $0.35 \%$ and $0.56 \%$ accuracies (of reading), respectively. A Bosch $\mathrm{CP} 3$ common-rail fuel injection pump and injector (maximum $\mathrm{P}_{\text {rail }}$ of $\sim 1500$ bar) were used for diesel injection. Diesel injection parameters were controlled by a National Instruments stand-alone diesel injection (SADI) driver coupled with CALVIEW software. An electronically controlled needle valve (HANBAY Model MCM-050AB) was used to control the flow rate of propane, which was fumigated in the intake manifold.

In-cylinder pressure was measured using a Kistler model $6052 \mathrm{C}$ pressure sensor and a Kistler Type 5010B charge amplifier. The diesel injector was instrumented with a Wolff Hall effect sensor to obtain needle lift data. Both sensors were phased with respect to crank angle using 
a BEI incremental shaft encoder with a resolution of 0.1 crank angle degree (CAD), which was coupled to the engine crankshaft. Cylinder pressure and needle lift data were recorded and averaged over 1000 consecutive cycles, and the intake manifold pressure was used to peg the cylinder pressure data at bottom dead center (BDC). It is well known from the literature that dual fuel combustion, utilizing diesel as the ignition source and any low cetane fuel as the primary fuel, tends to exhibit significant cyclic combustion variations depending on the concentration of primary fuel and engine operating parameters. In the present study, cyclic combustion variations over 1000 consecutive cycles were quantified as the coefficient of variation (COV) of net indicated mean effective pressure (IMEP), which is the ratio of the standard deviation in net IMEP to the arithmetic mean of the net IMEP expressed as a percentage.

To provide compressed air in the intake manifold, an Atlas Copco air compressor (Model GA75) coupled with a heatless desiccant dryer (Model CD 250) were used. Air flow rate was measured using a FlowMaxx sonic orifice flow meter (Model SN16-SA-235). To ensure choked flow across the sonic orifice, the pressure ratio across the orifice (inlet to outlet) was always maintained above a critical value of 1.2 at all engine operating conditions. The accuracies of various experimental measurements are provided in Table 2.

\subsection{Definitions}

Important combustion parameters used in this paper such as equivalence ratio $(\Phi)$, percent energy substitution (PES), ignition delay (ID), combustion efficiency $\left(\eta_{c}\right)$, net apparent heat release rate (AHRR), and specific heat ratio $(\gamma)$ are defined below:

$$
P E S=\frac{\dot{m}_{g} L H V_{g}}{\dot{m}_{d} L H V_{d}+\dot{m}_{g} L H V_{g}} \times 100 \%
$$




$$
\begin{gathered}
\Phi=\frac{(A / F)_{s t-t o t}}{\left(\frac{\dot{m}_{a}}{\dot{m}_{d}+\dot{m}_{g}}\right)} \\
I D=C A 5-S O I \\
\eta_{c}=1-\frac{\sum_{i} x_{i} Q_{L H V i}}{\left(\frac{\dot{m}_{f}}{\dot{m}_{f}+\dot{m}_{a}}\right) Q_{L H V f}} \\
A H R R(\theta)=\frac{\gamma}{\gamma-1} P \frac{d V}{d \theta}+\frac{1}{\gamma-1} V \frac{d P}{d \theta} \\
\gamma(T)=1.338-6 \times 10^{-5} T+1 \times 10^{-8} T^{2}
\end{gathered}
$$

In Equations 1 and 2, $\dot{m}$ refers to the mass flow rates of diesel (subscript $d$ ), gaseous methane fuel (subscript $g$ ), and air (subscript $a$ ), and $L H V$ refers to the corresponding fuel lower heating values. Stoichiometric air-fuel ratio $(A / F)_{\text {st-tot }}$ is defined as the stoichiometric air required for complete oxidation of both diesel and propane into $\mathrm{CO}_{2}$ and $\mathrm{H}_{2} \mathrm{O}$. Therefore, $(A / F)_{\text {st-tot }}$ is dependent on the PES of propane. In Equation 3, ignition delay is defined as the time elapsed from SOI to start of combustion (SOC), which is defined as the crank angle at which 5 percent of cumulative heat release occurs (CA5). Similarly, combustion phasing (CA50) and combustion duration (CA10-90) are defined as the crank angle at which 50 percent of cumulative heat release occurs and the difference between the 10 and 90 percent cumulative heat release crank angles, respectively.

In Equation 4, combustion efficiency $\left(\eta_{c}\right)$ is calculated using the mass fractions $\left(x_{i}\right)$ of $\mathrm{CO}$, $\mathrm{H}_{2}, \mathrm{HC}$, and PM using their respective LHVs $\left(Q_{L H V_{i}}\right)$ [46]. In this study, only the measured CO and $\mathrm{HC}$ concentrations and the $\mathrm{H}_{2}$ mass fractions estimated from stoichiometry calculations are 
used in the combustion efficiency calculations. Since the composition of HC in the exhaust, and thus its LHV, are not known, Heywood recommends using the LHV of the fuel as they are expected to be of comparable magnitude. However, since two fuels are used for dual fuel combustion, the exhaust $\mathrm{HC}$ can theoretically originate from both fuels; therefore, the combined mass-fractionweighted LHV of diesel and propane is used to represent the LHV of HC. The lower heating values for propane, $\mathrm{CO}$ and $\mathrm{H}_{2}$ are assumed to be $46.4 \mathrm{MJ} / \mathrm{kg}, 10.1 \mathrm{MJ} / \mathrm{kg}$, and $120 \mathrm{MJ} / \mathrm{kg}$, respectively. Also, since gravimetric PM was not measured in the present experiments, it was not considered in the combustion efficiency calculations.

The net apparent heat release rate (AHRR), which is defined as the difference between the gross heat release and the heat transfer rate to the cylinder walls, was derived from measured incylinder pressure data using Equation 5. The instantaneous volume ( $V$ ) was calculated from the engine geometry and derivatives of pressure and volume $(d P / d \theta$ and $d V / d \theta)$ were calculated numerically using a four point central difference formula. The specific heat ratio $(\gamma)$ required in Eq. 5 was evaluated as a function of mass averaged bulk gas temperature $(T)$ using Equation 6 [47].

\subsection{Experimental Procedure}

To characterize the effects of SOI, $\mathrm{P}_{\text {rail }}$, and $\mathrm{P}_{\text {in }}$ on combustion, performance, and emissions in diesel-propane dual fuel LTC, the experimental matrix shown in Table 3 was used. All experiments were performed at a constant net indicated mean effective pressure (IMEP) of 5.1 bar (which corresponded to a brake mean effective pressure (BMEP) of 3.3 bar), a fixed engine speed of $1500 \mathrm{rev} / \mathrm{min}$, a constant propane PES of 80 percent, and a nominal intake manifold temperature of $35^{\circ} \mathrm{C}$. Previous experimental results from the same SCRE [48] were used to determine that a propane PES of 80 percent provided a reasonable tradeoff between high engine instability, ISHC, 
and ISCO emissions on the one hand and excessively high cylinder pressures and maximum pressure rise rates (MPRR) on the other. Exhaust gas recirculation was not used in these experiments.

The engine load and speed chosen for these experiments need further explanation. The maximum cylinder pressure as well as the MPRR were important factors that affected the maximum achievable load (net IMEP) with dual fuel LTC on the SCRE. The "stock" compression ratio of the SCRE was 17.1:1; this high compression ratio was a primary cause for issues with maximum cylinder pressure and MPRR experienced during experiments. For the experiments reported in this paper, the maximum cylinder pressure and the MPRR were limited to about 120 bar and $10 \mathrm{bar} / \mathrm{CAD}$, respectively, to ensure safe engine operation. Consequently, the engine load was limited to 5.1 bar net IMEP. The engine speed was fixed at $1500 \mathrm{rev} / \mathrm{min}$, which is a typical maximum torque speed relevant to heavy-duty diesel engines.

\section{RESULTS AND DISCUSSION}

In this section, combustion, performance, and emissions results for diesel-propane LTC are presented for SOI, $\mathrm{P}_{\text {rail }}$, and $\mathrm{P}_{\text {in }}$ variations. The SOI effects are analyzed first to help identify the associated performance-emissions tradeoffs. Subsequently, the effects of $\mathrm{P}_{\text {rail }}$ and $\mathrm{P}_{\text {in }}$ are discussed at a $\mathrm{SOI}=310 \mathrm{CAD}$. Before discussing the results, it is perhaps pertinent to note the absolute crank angle degrees (CAD) terminology used in the present work. In the absolute CAD terminology, $0 \mathrm{CAD}$ is defined as the gas exchange TDC; therefore, the compression TDC occurs at $360 \mathrm{CAD}$. This choice of absolute CAD eliminates negative crank angles as well as the need to specify after TDC or before TDC along with the numerical crank angle value. 


\subsection{Effects of Start of Injection (SOI) of Diesel Fuel}

\subsubsection{Apparent Heat Release Rate and Cylinder Pressure}

As mentioned in Table 3, the SOI sweep was performed over a wide range of injection timings (from 280 to 355 CAD). Figures 2 and 3 illustrate the cylinder pressure and AHRR profiles for various SOIs. For reference, Fig. 3 also includes the measured needle lift histories and motoring pressure curves obtained for similar operating conditions. As the SOI is advanced from $355 \mathrm{CAD}$ to $330 \mathrm{CAD}$, the magnitude of peak cylinder pressure increases (up to $330 \mathrm{CAD}$ ) and the location of peak pressure shifts towards TDC. For further SOI advancement up to 280 CAD, the peak cylinder pressure decreases and occurs later in the expansion stroke. Simultaneously, as SOI is advanced from $355 \mathrm{CAD}$ to $280 \mathrm{CAD}$, the shape of the AHRR profile changes from twostage, diesel-like combustion to single-stage (nearly Gaussian) combustion.

As SOI is advanced to $330 \mathrm{CAD}$, the SOC occurs earlier, but with further SOI advancement, the SOC is increasingly delayed. For SOIs between 355 CAD and 330 CAD, two stage AHRR is observed. In general, the first stage heat release peak is higher (except for 350 CAD SOI) and occurs earlier as SOI is advanced. Also, the second stage heat release peak increases and reaches a maximum for 340 CAD SOI. For the SOI of 330 CAD, the lower second stage heat release peak can be explained by the earlier SOC and the combustion phasing, which indicates that the combustion process is nearly completed even before the piston reaches TDC. Also, the separation between the end of injection (EOI) and SOC is around 5 CAD for 330 CAD SOI while for 340 CAD SOI, SOC occurs even before EOI. As a result, the time available for mixing of the injected diesel with the propane-air mixture is longer for 330 CAD SOI compared to retarded SOIs. This leads to higher first stage AHRR (caused by the prepared fuel-air mixture) and lower second stage AHRR. 
The earlier occurrence of SOC as SOI is advanced from 355 CAD to 340 CAD and the separation between EOI and SOC can be explained with the help of the bulk gas temperatures. As evident from the needle lift profiles, for relatively retarded SOIs (330 CAD to 355 CAD) there is very little or no separation between EOI and SOC. This is because diesel injection is completed near TDC, where in-cylinder bulk gas temperatures are sufficiently high to ensure fast preignition reactions of the injected diesel, and SOC commences after relatively short ignition delay periods (as evident from Fig. 4). Consequently for these retarded SOIs, the time available for diesel to mix with the propane-air mixture is shorter, thereby leading to the distinct two-stage AHRR profiles.

As SOI is advanced to $320 \mathrm{CAD}$ and beyond, a single-stage, Gaussian AHRR profile is observed, indicating more homogeneous combustion. Also, SOC as well as the location of peak AHRR occur progressively later in the cycle when SOI is advanced from 320 to 280 CAD. For 320 CAD SOI, the peak AHRR is lower and is phased before TDC, while for all other advanced SOIs, the peak AHRR increases and occurs later. Between 330 and 320 CAD SOIs, there is clearly a transition point between two-stage, relatively heterogeneous combustion and single-stage, more homogeneous combustion. This is related to the increasing mixing time available for the injected diesel with the surrounding lean propane-air mixture. For example, for 320 CAD SOI, the EOI and SOC are separated by about $20 \mathrm{CAD}$, allowing sufficient time to attain a more homogenous diesel-propane-air mixture before ignition, which causes a smooth single-stage AHRR profile. In addition, for 320 CAD SOI, some low temperature heat release (LTHR) is visible before the main heat release. Typically, LTHR is exhibited by diesel or diesel-like fuels at temperatures below $850 \mathrm{~K}$ [49]. For $320 \mathrm{CAD}$ SOI, diesel is injected at a relatively low temperature and sufficient amount of stratification is still left at $340 \mathrm{CAD}$, when the temperature supports LTHR chemistry. 
Further SOI advancement increases the residence time to such an extent that the injected diesel becomes "well-mixed," thus suppressing the LTHR reactions.

\subsubsection{Ignition and Combustion Parameters}

Figure 4 shows the ignition delay (ID), the maximum pressure rise rate (MPRR), and coefficient of variation (COV) of IMEP while Fig. 5 shows CA5 (i.e., SOC), CA10-90 and CA50 at different SOIs. As SOI is advanced from $355 \mathrm{CAD}$ to $340 \mathrm{CAD}$, the ID is nearly constant but increases sharply for further advancement. On the other hand, as SOI is advanced from $355 \mathrm{CAD}$ to $340 \mathrm{CAD}$, the MPRR increases from $3.3 \mathrm{bar} / \mathrm{CAD}$ to $8.8 \mathrm{bar} / \mathrm{CAD}$ and decreases for further advancement. The CA10-90 decreases significantly from $25.3^{\circ}$ at $355 \mathrm{CAD}$ to $9.9^{\circ}$ at $310 \mathrm{CAD}$, and remains nearly invariant beyond that. As SOI is advanced from $355 \mathrm{CAD}$ to $340 \mathrm{CAD}$, both SOC and CA50 occur earlier in the cycle. These trends, coupled with the decrease in CA10-90, allow the combustion process to occur faster at earlier SOIs, increasing the magnitude of the second stage AHRR.

The CA50 is phased progressively later in the cycle when SOI is advanced beyond 330 CAD. For SOIs earlier than $330 \mathrm{CAD}$, longer IDs allows more residence time for the diesel fuel, creating increasingly homogeneous mixtures that eventually transform the combustion process from heterogeneous diesel-like combustion to homogeneous HCCI-like combustion. As the CA10-90 remains fairly constant (especially for SOIs earlier than 310 CAD) and the combustion phasing is progressively delayed, the MPRR decreases. On the other hand, the combustion process becomes relatively unstable for SOIs advanced beyond $300 \mathrm{CAD}$ or retarded beyond $340 \mathrm{CAD}$ evident from the COV of IMEP trend. This may be attributed to excessive mixing (causing over- 
leaning of the mixture) at advanced SOIs and to relatively late CA50s for retarded SOIs, which might increase the occurrence of partial misfire.

\subsubsection{Fuel Conversion Efficiency, Combustion Efficiency, and Emissions}

Figure 6 shows IFCE and combustion efficiency $\left(\eta_{c o m b}\right)$ trends at different SOIs while ISNOx and smoke trends are illustrated in Fig. 7. As shown in Fig. 6, IFCE and $\eta_{\text {comb }}$ increase significantly with the advancement of SOI from $355 \mathrm{CAD}$ to $340 \mathrm{CAD}$. These increases can be attributed to CA50 phasing closer to TDC and the increase in peak in-cylinder bulk gas temperatures (cf. Fig. 8), which lead to more complete combustion. As $\mathrm{SOI}$ is advanced beyond $340 \mathrm{CAD}, \eta_{\text {comb }}$ reaches a peak value of 92 percent at $330 \mathrm{CAD}$ and decreases slightly with any further SOI advancement. The slight decrease in $\eta_{c o m b}$ and IFCE at more advanced SOIs can be caused by overmixing, leading to higher ISCO (cf. Fig. 8), and CA50 phasing later in the engine cycle.

The ISNOx increases sharply from $3.5 \mathrm{~g} / \mathrm{kWh}$ at $355 \mathrm{CAD}$ to $9.4 \mathrm{~g} / \mathrm{kWh}$ at $340 \mathrm{CAD}$; however, further SOI advancement leads to a sharp decrease in ISNOx emissions, reaching 0.12 $\mathrm{g} / \mathrm{kWh}$ at $310 \mathrm{CAD}$ and remaining very low for more advanced SOIs. Similar trends have been observed with diesel-methane and diesel-gasoline dual fuel LTC on the same SCRE in past research efforts [34-36]. The ISNOx trends can be explained by analyzing the separation between SOC and EOI and time available for injected diesel fuel to mix with the surrounding lean propaneair mixture. For late SOIs (340-355 CAD), combustion occurs earlier and very little or no separation is observed between SOC and EOI.

As a result, the air-fuel mixture remains stratified when combustion starts (after an ignition delay period), resulting in higher local temperatures and higher ISNOx emissions. On the other hand, for SOIs of $320 \mathrm{CAD}$ and earlier, the separation between EOI and SOC progressively 
increases, creating increasingly homogeneous diesel-propane-air mixtures. The very low ISNOx levels achieved with sufficiently early SOIs (310 CAD and earlier) are the cumulative result of increased residence times, separation between EOI and SOC, and more complete fuel-air mixing, all of which lead to low local temperatures.

While smoke emissions are very low $(<0.1 \mathrm{FSN})$ for the entire range of SOIs, they show a slight decrease from 0.1 FSN at $355 \mathrm{CAD}$ SOI to $0.02 \mathrm{FSN}$ with SOI advancement. The overall low smoke emissions are due to high propane PES at all SOIs. The slight decrease with advancing SOI can be attributed to the increasingly homogenous nature of predominantly lean propanediesel-air mixtures during combustion. Despite the overall decrease in smoke emissions with SOI advancement, there is a very small (but noticeable) increase between the SOIs of 290 CAD and 280 CAD. While the actual reason for this small increase in smoke is unclear at this time, it may be speculated that this may be related to excessive penetration of the diesel sprays at $280 \mathrm{CAD}$ SOI, resulting in spray impingement on the cylinder walls and slightly higher smoke emissions.

Figure 8 shows the variations in ISHC and ISCO emissions as well as peak bulk gas temperatures (obtained using the ideal gas equation of state along with the measured cylinder pressure, cylinder volume, and trapped mass) versus SOI. When SOI is advanced from $350 \mathrm{CAD}$ to $330 \mathrm{CAD}$, ISHC emissions decrease from $\sim 50 \mathrm{~g} / \mathrm{kWh}$ to $15 \mathrm{~g} / \mathrm{kWh}$ while ISCO emissions decrease from $\sim 55 \mathrm{~g} / \mathrm{kWh}$ to $11 \mathrm{~g} / \mathrm{kWh}$. For further SOI advancement, ISHC remains nearly invariant; however, ISCO emissions increase again to $\sim 33 \mathrm{~g} / \mathrm{kWh}$ at $280 \mathrm{CAD}$ SOI. For the most retarded SOI of $355 \mathrm{CAD}$, the ISHC emissions are higher $(\sim 75 \mathrm{~g} / \mathrm{kWh})$ while ISCO emissions are lower $(46 \mathrm{~g} / \mathrm{kWh})$. These trends can be explained by analyzing bulk gas temperatures and the residence times of high temperatures. 
As the entire timing sweep is performed at a propane PES of 80 percent, unburned propane trapped in the crevices is likely one of the major sources of $\mathrm{HC}$ emissions. Additionally, for more unstable operating conditions characterized by high COV of IMEP, bulk quenching (leading to partial misfire) may also contribute to $\mathrm{HC}$ emissions. The sharp increase in ISHC emissions from $340 \mathrm{CAD}$ to $355 \mathrm{CAD}$ SOI may be attributed to a combination of factors, including extremely delayed onset of combustion (CA5) and combustion phasing (CA50) as well as significantly longer combustion durations (CA10-90 is 25 CAD for 355 CAD SOI) and higher COV of IMEP. In addition, relatively low peak bulk gas temperatures also limit HC oxidation rates for late SOIs as discussed below. For SOIs earlier than $340 \mathrm{CAD}$, the ISHC emissions are lower and remain relatively invariant because of more conducive CA50 and CA10-90 as well as higher peak bulk gas temperatures.

Residence times of high temperature regions play important roles in oxidizing both the HC and the $\mathrm{CO}$ formed during the combustion process. With dual fuel LTC, CO, which is an intermediate combustion species, may be formed both within the diesel jet periphery (for late SOIs when the jet does not completely disintegrate before ignition) as well as in the lean premixed propane-air mixture, which oxidizes following diesel ignition. If the jet remains intact during combustion for late SOIs, it is likely that the $\mathrm{CO}$ formed within the diesel jet is oxidized in the jet periphery, similar to conventional diesel combustion. However, a significant fraction of the $\mathrm{CO}$ formed in the lean, premixed propane-air mixture may remain unoxidized until the exhaust valve opens for the following possible reasons: (1) reduced availability of $\mathrm{OH}$ radicals, (2) inadequate mixing between high temperature and low temperature regions, and (3) insufficient time available for $\mathrm{CO}$ oxidation due to shorter combustion durations. 
It is well-known that the $\mathrm{CO}$ oxidation rate is directly proportional to the concentration of $\mathrm{OH}$ radicals, which can only be formed in high temperature regions. For complete oxidation of $\mathrm{CO}$ to $\mathrm{CO}_{2}$, local temperatures of at least $1500 \mathrm{~K}$ are needed under homogeneous conditions [50], along with the availability of $\mathrm{OH}$ radicals and sufficient residence times for these high-temperature regions. This critical $\mathrm{CO}$ oxidation temperature is independent of the nature of the hydrocarbon fuel because the reaction chemistry $\left(\mathrm{CO}+\mathrm{OH} \rightarrow \mathrm{CO}_{2}+\mathrm{H}\right)$ is fuel-independent. Now, the peak bulk gas temperature $\left(\mathrm{T}_{\text {peak-bulk}}\right.$ ) for different $\mathrm{SOIs}$ between $355 \mathrm{CAD}$ and $330 \mathrm{CAD}$ is $1050 \mathrm{~K}$ (355 CAD), $1135 \mathrm{~K}$ (350 CAD), $1253 \mathrm{~K}$ (340 CAD), 1342 K (330 CAD), decreases with further SOI advancement, and reaches the value of $1200 \mathrm{~K}$ at $280 \mathrm{CAD}$. As the peak temperature increases significantly between $355 \mathrm{CAD}$ and $330 \mathrm{CAD}$, a steep decrease in ISCO is observed except for $355 \mathrm{CAD}$. Despite having higher peak temperatures at $350 \mathrm{CAD}$ than $355 \mathrm{CAD}$, the increase in ISCO emissions is due to the competing effect of peak bulk temperature and residence time. The CA10-90 increases significantly from $20^{\circ}$ at $350 \mathrm{CAD}$ to $25^{\circ}$ at $355 \mathrm{CAD}$, and this counteracts the lower peak bulk gas temperature at $355 \mathrm{CAD}$, leading to more complete $\mathrm{CO}$ oxidation and lower $\mathrm{CO}$ emissions. Another possible contributor to this trend may be the fact that HC oxidation is likely inhibited at the lower bulk gas temperatures for $355 \mathrm{CAD}$ SOI, thus reducing CO formation. For SOIs between 330 and $280 \mathrm{CAD}$, ISCO emissions increase as a direct consequence of the decrease in peak bulk gas temperature from $1342 \mathrm{~K}$ to $1200 \mathrm{~K}$. However, ISHC emissions remain relatively invariant, providing credence to the hypothesis that $\mathrm{CO}$ oxidation to $\mathrm{CO}_{2}$ is the ratelimiting step at these operating conditions. 


\subsubsection{Efficiency-Emissions Tradeoffs for Different SOIs}

Figures 9 and 10 show ISNOx-IFCE, ISNOx-ISCO and ISNOx-ISHC tradeoff curves for different SOIs. These tradeoffs are helpful in finding the "optimum SOI" for these set of operating conditions. From Fig. 9, it is evident that as SOI is advanced from 355 CAD to 280 CAD, the ISNOx initially increases along with IFCE up to 340 CAD SOI and subsequently decreases sharply. For SOIs advanced to $310 \mathrm{CAD}$ and beyond, the ISNOx emissions are very low $(<0.2$ $\mathrm{g} / \mathrm{kWh}$ ) but the IFCE decreases slightly (by $\sim 1$ percent). It is clear from this tradeoff plot that the SOI of 310 CAD provides the "optimum" tradeoff between ISNOx $(0.12 \mathrm{~g} / \mathrm{kWh})$ and IFCE (45.7 percent).

On the other hand, Fig. 10 shows that as ISNOx increases with SOI advancement from 355 CAD, ISCO decreases down to $330 \mathrm{CAD}$ but increases thereafter. Clearly, for SOIs advanced beyond $310 \mathrm{CAD}$, the ISCO emissions continue to increase without any significant reduction in ISNOx. When the ISNOx-ISHC tradeoff is considered, it is evident that, for the same ISNOx behavior discussed above, the ISHC emissions decrease to a minimum at 320 CAD SOI but only increase marginally for more advanced SOIs. Consequently, it can be concluded that for these operating conditions, the SOI of $310 \mathrm{CAD}$ (with IFCE $\sim 45.7 \%$, ISNOx $\sim 0.12 \mathrm{~g} / \mathrm{kWh}$, ISHC $17.7 \mathrm{~g} / \mathrm{kWh}$, ISCO $\sim 18 \mathrm{~g} / \mathrm{kWh}$ ) is the "optimum SOI" vis-à-vis IFCE, ISNOx, ISCO, and ISHC. Therefore, the rail pressure and boost pressure experiments were performed with the SOI fixed at 310 CAD. 


\subsection{Effects of Rail Pressure (Prail)}

\subsubsection{Apparent Heat Release Rate and Cylinder Pressure}

It may be recalled from Table 3 that the $\mathrm{P}_{\text {rail }}$ studies were performed at $\mathrm{PES}=80 \%, \mathrm{SOI}=$ $310 \mathrm{CAD}$, and $\mathrm{P}_{\mathrm{in}}=1.5$ bar. Figure 11 shows cylinder pressure and AHRR profiles for selected

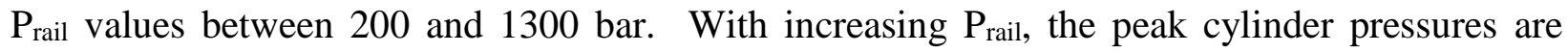
reduced and they occur progressively later in the engine cycle. These trends can be explained by considering the shape and phasing of the AHRR curves at different $\mathrm{P}_{\text {rail. }}$. At $\mathrm{P}_{\text {rail }}=200$ bar, the AHRR curve shows what appears to be a two-stage profile even at $\mathrm{SOI}=310 \mathrm{CAD}$. As $\mathrm{P}_{\text {rail }}$ is increased to 400 bar and beyond, the AHRR curve transitions to a single-stage Gaussian profile. When $P_{\text {rail }}$ is increased from 200 to 800 bar, the magnitude of peak AHRR increases while the phasing of the AHRR curve shifts to later in the engine cycle. However, increasing $P_{\text {rail }}$ from 800 bar to 1300 bar reduces the peak AHRR while the phasing continues to occur later.

\subsubsection{Ignition and Combustion Parameters}

As evident from Fig. 12, the ignition delay progressively increases from about $37 \mathrm{CAD}$ to 50 CAD with increasing $P_{\text {rail }}$ from 200 bar to 1300 bar. These long ignition delays, coupled with the fact that diesel is injected at $310 \mathrm{CAD}$, imply that sufficient time is available for mixing of diesel with the propane-air mixture for all $\mathrm{P}_{\text {rail. }}$ However, the mixing rate is affected by the value of $\mathrm{P}_{\text {rail. }}$ The rate of entrainment of the propane-air mixture into the diesel jet is proportional to the fuel jet velocity at the nozzle exit, the nozzle orifice diameter, the liquid length, and the densities of the liquid fuel and air [51]. In this particular set of experiments, when $P_{\text {rail }}$ is increased, the diesel jet velocity at nozzle exit is the primarily variable that is affected, which, in turn, affects the entrainment rate. Other parameters such as the nozzle orifice diameter (same injector) and the 
surrounding air density (SOI) were invariant with $\mathrm{P}_{\text {rail. }}$ In addition, it is well known [51] that the liquid length is unaffected by the nozzle orifice pressure drop (i.e., rail pressure alone for a fixed SOI, where cylinder pressure remains invariant) for pressure drops between 500 and 1750 bar; however, it is not clear if this trend can be extrapolated to lower rail pressures. Nevertheless, as $\mathrm{P}_{\text {rail }}$ is increased from 200 bar to 1300 bar in the present set of experiments, the entrainment and mixing rates likely increase due to higher injection velocities. This enhances the vaporization rates of the diesel jet with increasing $\mathrm{P}_{\text {rail, }}$ and consequently, the diesel-propane-air mixture is increasingly homogeneous. Moreover, for $\mathrm{P}_{\text {rail }}=200 \mathrm{bar}$, the ignition delay (and mixing time) is shorter compared to $P_{\text {rail }}=1300$ bar. Finally, it was evident from the needle lift profiles (not shown here) that the difference in EOI between $\mathrm{P}_{\text {rail }}$ of 200 bar and 1300 bar is almost 7 CAD. So, the higher mixing rates coupled with the longer time available for mixing lead to more homogeneous combustion at higher $\mathrm{P}_{\text {rail }}$ values.

In light of these observations, the trends in AHRR can be explained as follows. As $\mathrm{P}_{\text {rail }}$ is increased, mixing rates and ignition delays increase, combustion becomes more homogeneous, and is phased progressively later in the engine cycle. These trends are mirrored in the CA5 and CA50 trends shown in Fig. 13, which are increasingly delayed as $\mathrm{P}_{\text {rail }}$ is increased. Conversely, for low $\mathrm{P}_{\text {rail }}$ (e.g., 200 bar), the combustion is relatively more heterogeneous and occurs earlier.

Also evident from Fig. 12 are MPRR and COV of IMEP trends with $\mathrm{P}_{\text {rail. }}$ Overall, very low COV of IMEP values indicate that combustion stability was unaffected by $\mathrm{P}_{\text {rail. }}$ The MPRR attains a maximum value of $7.6 \mathrm{bar} / \mathrm{CAD}$ at $\mathrm{P}_{\text {rail }}=800 \mathrm{bar}$, and generally decreases for higher or lower $\mathrm{P}_{\text {rail. }}$ This is also reflected in the AHRR profiles exhibiting the highest peak heat release rate. This increase in peak AHRR is due to the combined effect of both CA5 and CA50 being phased closer to TDC at $\mathrm{P}_{\text {rail }}=800$ bar. However, by comparison, CA10-90 decreases sharply 
from $13 \mathrm{CAD}$ to $7.5 \mathrm{CAD}$ as $\mathrm{P}_{\text {rail }}$ is increased from 200 bar to 800 bar. This may be attributed to the increasingly homogeneous nature of the combustion process as $\mathrm{P}_{\text {rail }}$ is increased from 200 bar to 800 bar, which causes progressively faster combustion and shorter combustion durations. However, beyond $\mathrm{P}_{\text {rail }}=800$ bar, the increase in homogeneity is apparently minimal, and as CA5 is already very close to TDC and CA50 occurs later in the expansion stroke, resulting in nearly invariant CA10-90.

\subsubsection{Performance and Emissions}

With increasing $P_{\text {rail, }}$ the IFCE variations were relatively small and hence not shown here. The IFCE changed from 45.9 percent at 200 bar to 46.9 percent at 1300 bar, with the highest IFCE of 47.5 percent achieved at 1000 bar. For $\mathrm{P}_{\text {rail }}=1000$ bar, CA50 was the closest to TDC and CA10-90 was the shortest; therefore, a slight increase in IFCE was observed. Combustion efficiency remained relatively invariant ( 88-91 percent) with increasing $\mathrm{P}_{\text {rail. }}$.

As shown in Fig. 14, ISNOx decreases exponentially from $2.4 \mathrm{~g} / \mathrm{kWh}$ at $\mathrm{P}_{\text {rail }}=200$ bar to $0.12 \mathrm{~g} / \mathrm{kWh}$ at $\mathrm{P}_{\text {rail }}=500$ bar but remains nearly invariant with further increase in $\mathrm{P}_{\text {rail. }}$. Extremely high ISNOx levels at $\mathrm{P}_{\mathrm{rail}}=200$ bar can be attributed to lower entrainment rates, shorter separation between EOI and SOC, and more heterogeneous combustion that leads to higher local temperatures that favor thermal NO formation. On the other hand, as $\mathrm{P}_{\text {rail }}$ increases, the separation between EOI and SOC increases, combustion occurs in increasingly lean, homogeneous, mixtures,

resulting in lower local temperatures and lower ISNOx. Smoke emissions $(<0.1 \mathrm{FSN})$ remained essentially invariant with $\mathrm{P}_{\text {rail, }}$ and hence, are not shown here.

The ISHC and ISCO emissions as well as peak bulk gas temperature trends vs $\mathrm{P}_{\text {rail }}$ are shown in Fig. 14. In general, both ISHC and ISCO emissions decrease slightly with decreasing 
rail pressures. The only exception to these trends is evident at $\mathrm{P}_{\text {rail }}=600$ bar. The ISHC and ISCO trends can be explained by considering the peak bulk gas temperatures and the associated residence times. As mentioned earlier, higher peak bulk gas temperatures and longer residence times favor HC and CO oxidation. However, peak bulk gas temperature typically has a more significant effect than residence time, and therefore, increases or decreases in $\mathrm{HC}$ and $\mathrm{CO}$ emissions are governed by the relative dominance of these two parameters. As $\mathrm{P}_{\text {rail }}$ is increased from 200 bar to 600 bar, peak bulk gas temperature and CA10-90 decrease, leading to higher ISHC and ISCO. At $\mathrm{P}_{\text {rail }}=$ 800 bar, though the residence time decreases compared to $P_{\text {rail }}=600$ bar, a relatively higher peak bulk gas temperature helps oxidize more $\mathrm{HC}$ and CO. For $\mathrm{P}_{\text {rail }}$ above 800 bar, CA10-90 is nearly constant and the $\mathrm{HC}$ and $\mathrm{CO}$ oxidation rates depend more on the peak bulk gas temperature; consequently, as $\mathrm{P}_{\text {rail }}$ is increased beyond 800 bar, the peak bulk gas temperature decreases, increasing ISHC and ISCO.

\subsection{Effects of Intake Boost Pressure $\left(P_{i n}\right)$}

\subsubsection{Apparent Heat Release Rate and Cylinder Pressure}

Figure 15 shows cylinder pressure and AHRR profiles for selected $\mathrm{P}_{\text {in }}$ from 1.1 to 1.8 bar at $\mathrm{PES}=80 \%, \mathrm{SOI}=310 \mathrm{CAD}$, and $\mathrm{P}_{\text {rail }}=500$ bar. For reference, the corresponding motoring pressure traces are also provided at different $\mathrm{P}_{\text {in }}$. Since SOI, $\mathrm{P}_{\text {rail }}$, and PES are fixed for this set of experiments, the primary cause of the observed effects can be attributed to $\mathrm{P}_{\text {in }}$. It is also important to note that as $\mathrm{P}_{\text {in }}$ is increased, to maintain the IMEP constant at 5.1 bar, the diesel and propane mass flow rates had to be changed. Therefore, as $\mathrm{P}_{\text {in }}$ is increased from 1.1 to $1.8 \mathrm{bar}$, the overall equivalence ratio decreases from 0.4 to 0.22 . As $\mathrm{P}_{\text {in }}$ is increased from 1.1 to 1.8 bar, it is evident 
that the peak cylinder pressures increase and occur earlier in the engine cycle. This may be expected due to the higher in-cylinder temperatures associated with the higher $\mathrm{P}_{\text {in. }}$.

The AHRR profiles show an interesting trend with $\mathrm{P}_{\text {in. }}$ It is evident that the AHRR curves exhibit single-stage Gaussian profiles for all $\mathrm{P}_{\mathrm{in}}$, (since SOI was fixed at $310 \mathrm{CAD}$ ), although the AHRR varies in rate and magnitude with $\mathrm{P}_{\text {in }}$. As $\mathrm{P}_{\text {in }}$ is increased from 1.1 to 1.8 bar, the AHRR curve is phased earlier in the engine cycle. Moreover, as $\mathrm{P}_{\text {in }}$ is increased from 1.1 to 1.3 bar, the peak AHRR increases but for further increase in $\mathrm{P}_{\text {in }}$, the peak AHRR decreases. As $\mathrm{P}_{\text {rail }}$ is kept constant, the initial momentum of the diesel spray remains unaffected by varying $\mathrm{P}_{\mathrm{in}}$. However, the equivalence ratio of the premixed propane-air mixture surrounding the diesel spray as well as the overall equivalence ratio decrease with increasing $\mathrm{P}_{\mathrm{in}}$. Also, as $\mathrm{P}_{\text {in }}$ increases, the mass of air trapped in the cylinder at IVC, the initial pressure at IVC, and the in-cylinder pressures and temperatures during compression increase.

Considering these observations, the AHRR trends can be explained as follows. As $\mathrm{P}_{\text {in }}$ is increased from 1.1 to $1.8 \mathrm{bar}$, the higher trapped mass and in-cylinder pressures lead to higher densities at SOI, likely resulting in higher entrainment rates of leaner propane-air mixtures into the diesel jet. While this might be expected to delay the AHRR phasing at higher $\mathrm{P}_{\mathrm{in}}$, such a trend is not observed: in fact, the AHRR phasing is advanced as $\mathrm{P}_{\text {in }}$ is increased. This is because, with increasing $\mathrm{P}_{\mathrm{in}}$, the higher in-cylinder pressures during compression also lead to higher in-cylinder bulk gas temperatures at higher $\mathrm{P}_{\mathrm{in}}$; e.g., the in-cylinder bulk gas temperature at SOI increases from $504 \mathrm{~K}$ at $\mathrm{P}_{\mathrm{in}}=1.1$ bar to $529 \mathrm{~K}$ at $\mathrm{P}_{\mathrm{in}}=1.8$ bar. Consequently, despite having leaner propaneair mixtures at higher $\mathrm{P}_{\mathrm{in}}$, the higher bulk gas temperatures facilitate earlier diesel autoignition and more advanced AHRR phasing. It may also be noted that there is a slight (but noticeable) increase in the magnitude of LTHR with increasing $\mathrm{P}_{\mathrm{in}}$, which leads to earlier onset of the main combustion 
process at higher $\mathrm{P}_{\text {in. }}$. The highest peak AHRRs are observed for intermediate $\mathrm{P}_{\text {in }}$ values due to a combination of the time available for diesel-propane-air mixture preparation as well as phasing of the AHRR with respect to TDC.

\subsubsection{Ignition and Combustion Parameters}

Figure 16 shows ID, MPRR and COV of IMEP, while Fig. 17 presents CA5, CA50, and CA10-90 at different $\mathrm{P}_{\text {in. }}$ For reasons discussed above, the ID decreases while CA5 and CA50 occur earlier with increasing $\mathrm{P}_{\mathrm{in}}$. The combustion duration (CA10-90) reaches a minimum (7.7 CAD) at $\mathrm{P}_{\text {in }}=1.3$ bar and increases if $\mathrm{P}_{\text {in }}$ higher or lower than 1.3 bar. The opposite trend is observed for MPRR, which peaks at 7.5 bar/CAD for $\mathrm{P}_{\mathrm{in}}=1.4$ bar. Combustion is phased just after TDC for $\mathrm{P}_{\mathrm{in}}=1.4$ bar, and advances or retards based on whether $\mathrm{P}_{\text {in }}$ is increased or decreased from there.

Interestingly, the maximum peak AHRR values are also observed for $\mathrm{P}_{\text {in }}$ close to 1.3-1.4 bar. By comparison, a very high value of COV of $\operatorname{IMEP}(10.7$ percent $)$ is observed for $\mathrm{P}_{\mathrm{in}}=1.1$ bar, indicating partial misfire under these conditions, while the COV of IMEP decreases to about 1.4 percent for $\mathrm{P}_{\text {in }}=1.2$ bar and remains below 2 percent for higher $\mathrm{P}_{\text {in }}$. This can be attributed to very late combustion phasing for $\mathrm{P}_{\mathrm{in}}=1.1 \mathrm{bar}$, which causes most of the combustion process to occur late in the expansion stroke, enhancing the possibility of bulk quenching partially misfiring engine cycles. This is also corroborated by higher ISHC emissions at $\mathrm{P}_{\text {in }}=1.1$ bar as discussed later (cf. Fig. 19). 


\subsubsection{Fuel Conversion Efficiency, Combustion Efficiency, and Emissions}

Figure 18 shows IFCE and combustion efficiency variations with $\mathrm{P}_{\text {in. }}$ With increasing $\mathrm{P}_{\text {in, }}$ the IFCE increased from 43.7 percent at 1.1 bar to 48.7 percent at 1.8 bar. For $\mathrm{P}_{\text {in }}=1.1$ bar, the IFCE was very low due to partially misfiring cycles and high COV of IMEP. For $\mathrm{P}_{\text {in }}=1.8$ bar, even though CA50, CA10-90, and combustion efficiency were not optimal, the higher IFCE may be attributed to the significantly lower overall equivalence ratio of 0.22 compared to lower $\mathrm{P}_{\text {in }}$. Combustion efficiency also varied little ( 85-89 percent) with increasing $\mathrm{P}_{\text {in }}$ and reflected the ISCO and ISHC trends observed in Fig. 19.

Figure 19 shows ISHC, ISCO, ISNOx, and peak bulk gas temperatures at different $\mathrm{P}_{\text {in. }}$ As $P_{\text {in }}$ is increased from 1.1 to $1.8 \mathrm{bar}$, ISNOx decreases from $0.2 \mathrm{~g} / \mathrm{kWh}$ to $0.07 \mathrm{~g} / \mathrm{kWh}$. This may be attributed to the higher overall equivalence ratios at lower $\mathrm{P}_{\text {in }}$ that leads to higher local temperatures, favoring higher thermal NO formation. The smoke emissions remain very low $(<$ 0.1 FSN) and invariant with $\mathrm{P}_{\text {in }}$; so, they are not shown here. Interestingly, ISHC and ISCO show opposite trends with respect to $\mathrm{P}_{\text {in }}$. At $\mathrm{P}_{\text {in }}=1.1 \mathrm{bar}$, the ISHC emissions are the highest $(\sim 20.9$ $\mathrm{g} / \mathrm{kWh}$ ) while for $\mathrm{P}_{\text {in }}>1.1$ bar, the ISHC emissions are lower and remain invariant (15-16.5 $\mathrm{g} / \mathrm{kWh}$ ). Therefore, the ISHC trend may be attributed to partially misfiring cycles and high COV of IMEP at $\mathrm{P}_{\text {in }}=1.1$ bar. On the other hand, as $\mathrm{P}_{\text {in }}$ is increased from 1.2 to 1.8 bar, the ISCO emissions increase sharply from $6.5 \mathrm{~g} / \mathrm{kWh}$ to $30 \mathrm{~g} / \mathrm{kWh}$. These trends should be considered along with the peak bulk gas temperature, which decreases from $1390 \mathrm{~K}$ at $\mathrm{P}_{\text {in }}=1.2$ bar to $1245 \mathrm{~K}$ at $\mathrm{P}_{\text {in }}$ $=1.8$ bar. It is likely that the reduction in peak bulk gas temperature with increasing $\mathrm{P}_{\text {in }}$ decreases $\mathrm{CO}$ oxidation rates, resulting in higher ISCO emissions and lower combustion efficiencies, despite the higher availability of oxygen at higher $\mathrm{P}_{\text {in }}$ (due to lower overall equivalence ratios). 


\section{CONCLUSIONS}

Diesel-ignited propane dual fuel low temperature combustion (LTC) was characterized on a single-cylinder research engine (SCRE) at a constant engine speed of $1500 \mathrm{rpm}$ and a constant engine load of 5.1 bar net IMEP (3.3 bar BMEP). While keeping propane energy substitution (PES $=80 \%)$ and intake manifold temperature $\left(\mathrm{T}_{\text {in }}=35^{\circ} \mathrm{C}\right)$ constant, parametric studies were performed over a range of diesel injection timings $(\mathrm{SOI}=280-355 \mathrm{CAD})$, diesel rail pressures $\left(\mathrm{P}_{\text {rail }}=200\right.$ - 1300 bar), and boost pressures ( $\mathrm{P}_{\mathrm{in}}=1.1-1.8 \mathrm{bar}$ ). Analysis of the results led to the following salient conclusions:

1. Diesel-propane dual fuel combustion is profoundly affected by diesel SOI. As SOI is advanced from $355 \mathrm{CAD}$ to $280 \mathrm{CAD}$, the onset of combustion is increasingly separated from the diesel injection event (i.e., ignition delay increased) and the apparent heat release rate (AHRR) curves transitioned from two-stage "diesel-like" combustion to single-stage Gaussian profiles (representative of homogeneous combustion processes) between 330 CAD SOI and 320 CAD SOI. Incidentally, the phasing of the AHRR curve occurs earlier in the engine cycle as SOI is advanced from $355 \mathrm{CAD}$ to $330 \mathrm{CAD}$ but is increasingly delayed for further SOI advancement.

2. Diesel-propane LTC is achieved for SOIs earlier than 310 CAD with very low ISNOx emissions $(0.12 \mathrm{~g} / \mathrm{kWh})$ and smoke emissions $(<0.1 \mathrm{FSN})$ and high indicated fuel conversion efficiencies (IFCE $\sim 46 \%)$; however, ISCO emissions are high for very late SOIs $(\sim 50 \mathrm{~g} / \mathrm{kWh})$ and very early SOIs $(\sim 30 \mathrm{~g} / \mathrm{kWh})$ while ISHC emissions are high for very late SOIs $(\sim 75$ $\mathrm{g} / \mathrm{kWh}$ ). Maximum pressure rise rates (MPRRs) are high for intermediate SOIs while COV of IMEP is high for very early and very late SOIs. Efficiency-emissions tradeoffs indicated an "optimal" SOI of $310 \mathrm{CAD}$ under these conditions, which was chosen for further studies at different $\mathrm{P}_{\text {rail }}$ and $\mathrm{P}_{\text {in. }}$. 
3. As $\mathrm{P}_{\text {rail }}$ is increased from 200 bar to 1300 bar, the peak cylinder pressure decreases, the onset of ignition occurs later, the AHRR is increasingly retarded, and combustion becomes progressively more homogeneous. Consequently, with increasing $\mathrm{P}_{\text {rail, }}$ ISNOx emissions decreased and ISCO and ISHC emissions increased slightly but IFCE remained nearly invariant. From this study, an "optimal" Prail of about 500 bar was identified for these operating conditions.

4. Increasing $P_{\text {in }}$ from 1.1 to 1.8 bar decreased the overall equivalence ratio from 0.4 to 0.22 , increased peak in-cylinder pressures, reduced ignition delays, and advanced AHRR profiles, with higher peak AHRRs occurring at intermediate $\mathrm{P}_{\text {in. }}$ While IFCE increased from $43.7 \%$ at 1.1 bar to $48.7 \%$ at 1.8 bar and ISNOx and ISHC decreased slightly, ISCO increased sharply from $\sim 7 \mathrm{~g} / \mathrm{kWh}$ to $30 \mathrm{~g} / \mathrm{kWh}$ due to lower bulk gas temperatures at higher $\mathrm{P}_{\text {in. }}$ A $\mathrm{P}_{\text {in }}$ between 1.4 and 1.5 bar yielded optimal efficiency-emissions tradeoffs.

The experimental results reported in this paper demonstrate the benefits (IFCE, ISNOx, and smoke) as well as the challenges (ISHC, ISCO, COV of IMEP, and MPRR) associated with diesel-ignited propane dual fuel LTC through a series of experiments performed at one engine load and speed (5.1 bar net IMEP and $1500 \mathrm{rev} / \mathrm{min}$ ). Additional research is needed to characterize performance-emissions tradeoffs at other engine speeds and loads. Specifically, for expanding the operating range of dual fuel LTC, it is imperative to devise strategies for mitigating the primary challenges of higher ISCO and ISHC emissions and higher COV of IMEP that limit low load operation and higher MPRR that limit high load operation. 


\section{ACKNOWLEDGMENTS}

The authors gratefully acknowledge gratefully acknowledge financial support from the Sustainable Energy Research Center (US DOE Award \# DE-FG36-06GO86025) and facilities support from the Center for Advanced Vehicular Systems at Mississippi State University

\section{REFERENCES}

1. Yao, M., Zheng, Z., Liu, H., (2009) "Progress and recent trends in homogeneous charge compression ignition (HCCI) engines." Progress in Energy and Combustion Science, 25, 398437.

2. Noehre, C., Andersson, M., Johansson, B., Hultqvist, A., (2006) "Characterization of partially premixed combustion.” SAE Technical Paper 2006-01-3412.

3. Musculus, M.P.B., Miles, P.C., Pickett, L.M., (2013) "Conceptual models for partially premixed low-temperature diesel combustion," Progress in Energy and Combustion Science, 39, 246-283.

4. Kalghatgi, G.T., Risberg, P., Angstrom, H.-E., (2007) "Partially pre-mixed auto-ignition of gasoline to attain low smoke and low NOx at high load in a compression ignition engine and comparison with a diesel fuel.” SAE Technical Paper 2007-01-0006.

5. Ciatti, S.A., Subramanian, S., (2011) “An experimental investigation of low-octane gasoline in diesel engines." Trans. ASME: Journal of Engineering for Gas Turbines and Power, 133(9), 092802, doi:10.1115/1.4002915

6. Krishnan, S.R., Srinivasan, K.K., Singh, S., Bell, S.R., Midkiff, K.C., Gong, W., Fiveland, S.B., Willi, M., (2004) "Strategies for Reduced NOx Emissions in Pilot-Ignited Natural Gas Engines." Trans. ASME: Journal of Engineering for Gas Turbines and Power, 126, 665-671.

7. Srinivasan, K.K., Krishnan, S.R., Singh, S., Midkiff, K.C., Bell, S.R., Gong, W., Fiveland, S.B., Willi, M. (2006) "The Advanced Injection Low Pilot Ignited Natural Gas Engine: A Combustion Analysis." ASME Journal of Engineering for Gas Turbines and Power, Vol. 128, 213-218.

8. Azimov, U., Tomita, E., Kawahara, N., Harada, Y., (2011) "Premixed mixture ignition in the end-gas region (PREMIER) combustion in a natural gas dual-fuel engine: operating range and exhaust emissions." International Journal of Engine Research, 12, 484-497. 
9. Li, W., Liu, Z., Wang, Z., (2016) "Experimental analysis and theoretical analysis of the combustion process at low loads of a diesel natural gas dual-fuel engine." Energy, 94, 728741.

10. Kokjohn, S.L., Hanson, R.M., Splitter, D.A., Reitz, R.D., (2011) "Fuel reactivity controlled compression ignition (RCCI): A pathway to controlled high-efficiency clean combustion." International Journal of Engine Research, 12(3), 209-226.

11. Elliot, M.A., Davis, R.F. (1951) "Dual-fuel combustion in diesel engines," Industrial and Engineering Chemistry, 43 (12), 2854-2864.

12. Felt, A.E., Steele, W.A., Jr. (1962) "Combustion control in dual-fuel engines," Transactions of the Society of Automotive Engineers, 70, 644-653.

13. Karim, G.A., Khan, M.O. (1968) "Examination of effective rates of combustion heat release in a dual-fuel engine," Proceedings of the Institution of Mechanical Engineers: Journal of Mechanical Engineering Science, 10(1), 13-23.

14. Karim, G.A. (1980) "A review of combustion processes in the dual fuel engine - the gas diesel engine," Progress in Energy and Combustion Science, 6, 277-285.

15. Doughty, G.E., Bell, S.R., Midkiff, K.C. (1992). "Natural gas fueling of a Caterpillar 3406 diesel engine." Trans. ASME: Journal of Engineering for Gas Turbines and Power, 114, 459465.

16. Selim, M.Y.E. (2005). "Effect of engine parameters and gaseous fuel type on the cyclic variability of dual fuel engines." Fuel, 84, 961-971.

17. Carlucci, A.P., de Risi, A., Laforgia, D., Naccarato, F. (2008) “Experimental investigation and combustion analysis of a direct injection dual-fuel diesel-natural gas engine." Energy, 33, 256-263.

18. Sahoo, B.B., Sahoo, N., Saha, U.K., (2009) "Effect of engine parameters and type of gaseous fuel on the performance of dual-fuel gas diesel engines - A review." Renewable and Sustainable Energy Reviews, 13, 1151-1184.

19. Korakianitis, T., Namasivayam, A.M., Crookes, R.J. (2011) "Natural-gas fueled sparkignition (SI) and compression-ignition (CI) engine performance and emissions," Progress in Energy and Combustion Science, 37(1), 89-112. doi: 10.1016/j.pecs.2010.04.002

20. Lounici, M.S., Loubar, K., Tarabet, L., Balistrou, M., Niculescu, D.-C., Tazerout, M., (2014) "Towards improvement of natural gas-diesel dual fuel mode: An experimental investigation on performance and exhaust emissions." Energy, 64, 200-211.

21. Tarabet, L., Loubar, K., Lounici, M.S., Khiari, K., Belmrabet, T., Tazerout, M., (2014) "Experimental investigation of DI diesel engine operating with eucalyptus biodiesel/natural gas under dual fuel mode." Fuel, 133, 129-138. doi:10.1016/j.fuel.2014.05.008 
22. Wei, L., Geng, P., (2016) “A review of natural gas/diesel dual fuel combustion, emissions and performance." Fuel Processing Technology, 142, 264-278.

23. Krishnan, S.R., Biruduganti, M., Mo, Y., Bell, S.R., Midkiff K.C. (2002). "Performance and heat release analysis of a pilot-ignited natural gas engine." International Journal of Engine Research, 3(3), 171-184.

24. Papagiannakis, R.G., Hountalas, D.T. (2003) "Experimental Investigation Concerning The Effect of Natural Gas Percentage on Performance and Emissions of a DI Dual Fuel Diesel Engine" Applied Thermal Engineering, 23, 353-365.

25. Karim, G.A., (2003) "Combustion in Gas Fueled Compression: Ignition Engines of the Dual Fuel Type.” Trans. ASME: Journal of Engineering for Gas Turbines and Power, 125, 827836.

26. Papagiannakis, R.G., Rakopoulos, C.D., Hountalas, D.T., Rakopoulos, D.C. (2010) "Emission characteristics of high speed, dual fuel, compression ignition engine operating in a wide range of natural gas/diesel fuel proportions." Fuel, 89(7), 1397-1406.

27. Dec, J.E., (1997) "A Conceptual Model of DI Diesel Combustion Based on Laser-Sheet Imaging." SAE Technical Paper 970873.

28. Tomita, E., Kawahara, N., Piao, Z., Yamaguchi, R. (2002). "Effects of EGR and early injection of diesel fuel on combustion characteristics and exhaust emissions in a methane dual fuel engine." SAE Technical Paper 2002-01-2723.

29. Singh, S., Krishnan, S.R., Srinivasan, K.K., Midkiff, K.C., Bell, S.R. (2004). "Effect of pilot injection timing, pilot quantity and intake charge conditions on performance and emissions for an advanced low-pilot ignited natural gas engine." International Journal of Engine Research, 5(4), 329-348.

30. Srinivasan, K.K., Krishnan, S.R., Qi, Y., Midkiff, K.C., Yang, H. (2007) "Analysis of Diesel Pilot-Ignited Natural Gas Low-Temperature Combustion with Hot Exhaust Gas Recirculation." Combustion Science and Technology, 179: 1737-1776.

31. Qi, Y., Srinivasan, K.K., Krishnan, S.R., Yang, H., Midkiff, K.C. (2007) "Effect of hot exhaust gas recirculation on the performance and emissions of an advanced injection low pilotignited natural gas engine.” International Journal of Engine Research, 8(3), 289-303.

32. Walker, N.R., Wissink, M.L., DelVescovo, D.A., Reitz, R.D. (2015) "Natural gas for high load dual-fuel reactivity controlled compression ignition in heavy-duty engines." Trans. ASME: Journal of Energy Resources Technology, 137(4), 042202 (7 pages); doi: 10.1115/1.4030110.

33. Reitz, R.D., Duraisamy, G., (2015) "Review of high efficiency and clean reactivity controlled compression ignition (RCCI) combustion in internal combustion engines." Progress in Energy and Combustion Science, 46, 12-71. 
34. Raihan, M.S., Guerry, E.S., Dwivedi U., Srinivasan K.K., Krishnan, S.R., (2014) "Experimental analysis of diesel-ignited methane dual fuel low temperature combustion in a single cylinder diesel engine." Trans ASCE: Journal of Energy Engineering, C4014007. doi: 10.1061/(ASCE)EY.1943-7897.0000235.

35. Guerry, E.S., Raihan, M.S., Srinivasan, K.K., Krishnan, S.R., Sohail, A., (2016) "Injection timing effects on partially premixed diesel-methane dual fuel low temperature combustion." Applied Energy, 162, 99-113.

36. Dwivedi, U., Carpenter, C.D., Guerry, E.S., Polk, A.C., Krishnan, S.R., Srinivasan, K.K., (2014). "Performance and emissions characteristics of diesel-ignited gasoline dual fuel combustion in a single cylinder research engine. Trans. ASME: Journal of Engineering for Gas Turbines and Power, 136(10), 101504 (10 pages), doi: 10.1115/1.4027273.

37. Fang, W., Fang, J., Kittelson, D.B., Northrop, W.F., (2015) “An experimental investigation of reactivity-controlled compression ignition combustion in a single-cylinder diesel engine using hydrous ethanol." Trans. ASME: Journal of Energy Resources Technology, 137(3), 031101 (7 pages); doi: 10.1115/1.4028771.

38. Ma, Z., Huang, Z., Li, C., Wang, X., Miao, H. (2008) "Combustion and emission characteristics of a diesel engine fuelled with diesel-propane blends." Fuel, 87(8-9), 17111717. doi:10.1016/j.fuel.2007.09.011.

39. Saleh, H.E. (2008) "Effect of variation in LPG composition on emissions and performance in a dual fuel diesel engine." Fuel, 87(13-14), 3031-3039. doi:10.1016/j.fuel.2008.04.007.

40. Polk, A.C., Gibson, C.M., Shoemaker, N.T., Srinivasan, K.K., Krishnan, S.R. (2011) "Analysis of ignition behavior in a turbocharged direct injection dual fuel engine using propane and methane as primary fuels." Trans. ASME: Journal of Energy Resources Technology, 135(3), 032202 (10 pages); doi: 10.1115/1.4023482.

41. Goldsworthy, L., (2012) "Combustion behaviour of a heavy duty common rail marine diesel engine fumigated with propane." Experimental Thermal and Fluid Science, 42, 93-106; doi: 10.1016/j.expthermflusci.2012.04.016.

42. Polk, A. C., Carpenter, C. D., Srinivasan, K. K., Krishnan, S. R., (2014) "An investigation of diesel-ignited propane dual fuel combustion in a heavy-duty diesel engine." Fuel, 132, 135148. doi: 10.1016/j.fuel.2014.04.069.

43. Surawski, N.C., Miljevic, B., Bodisco, T.A., Situ, R., Brown, R.J., Ristovski, Z.D. (2014) "Performance and gaseous and particle emissions from a liquefied petroleum gas (LPG) fumigated compression ignition engine." Fuel, 133, 17-25. doi:10.1016/j.fuel.2014.04.093.

44. Polk, A.C. (2013) Detailed characterization of conventional and low temperature dual fuel combustion in compression ignition engines, Ph.D. dissertation, Mississippi State University, Mississippi State, MS. 
45. Polk, A.C., Carpenter, C.D., Guerry, E.S., Dwivedi, U., Srinivasan, K.K., Krishnan, S.R., (2014). "Diesel-ignited propane dual fuel low temperature combustion in a heavy-duty diesel engine." Trans. ASME: Journal of Engineering for Gas Turbines and Power, 136(9), 091509 (9 pages); doi: 10.1115/1.4027189.

46. Heywood, J.B. (1988) Internal Combustion Engine Fundamentals, McGraw-Hill, New York.

47. Brunt, M.F.J., Rai, H., Emtage, A.L., (1998) "The calculation of heat release energy from engine cylinder pressure data.” SAE Technical Paper 981052.

48. Raihan, M.S. (2014) A comparative study of diesel ignited methane and propane dual fuel low temperature combustion in a single cylinder research engine, M.S. thesis, Mississippi State University, Mississippi State, MS.

49. Saxena, S., Bedoya, I.D., (2013) "Fundamental phenomena affecting low temperature combustion and HCCI engines, high load limits and strategies for extending these limits." Progress in Energy and Combustion Science, 39, 457-488; doi: 10.1016/j.pecs.2013.05.002.

50. Sjöberg, M., Dec, J.E., (2005) "An investigation into lowest acceptable combustion temperatures for hydrocarbon fuels in HCCI engines." Proc. Combustion Institute, 30, 2719 2726; doi: 10.1016/j.proci.2004.08.132.

51. Siebers, D.L. (1999) "Scaling liquid-phase fuel penetration in diesel sprays based on mixinglimited vaporization." SAE Technical Paper 1999-01-0528. 
Table 1. Single-Cylinder Research Engine Details

\begin{tabular}{|c|c|}
\hline Engine Type & $\begin{array}{l}\text { RSi-130 DV11 single-cylinder research } \\
\text { engine, 4-stroke, compression-ignition }\end{array}$ \\
\hline Bore $\times$ Stroke & $128 \mathrm{~mm} \times 142 \mathrm{~mm}$ \\
\hline Connecting rod length & $228 \mathrm{~mm}$ \\
\hline Displaced Volume & $1827 \mathrm{~cm}^{3}$ \\
\hline Compression ratio (nominal) & $17.1: 1$ \\
\hline Valve train system & 4 overhead valves with pushrod \\
\hline Intake valve open (CAD absolute) & actuation \\
\hline Intake valve close (CAD absolute) & $32^{\circ}$ \\
\hline Exhaust valve open (CAD absolute) & $198^{\circ}$ \\
\hline \multirow[t]{2}{*}{ Exhaust valve close (CAD absolute) } & $532^{\circ}$ \\
\hline & $14^{\circ}$ \\
\hline Diesel fuel injection system & Bosch CP3 common-rail \\
\hline Injection nozzle hole diameter & $0.197 \mathrm{~mm}$ \\
\hline Number of nozzle holes & 8 \\
\hline Gaseous (propane) fueling & Fumigation into intake manifold \\
\hline \multirow[t]{2}{*}{ Aspiration } & Boosted intake (with external \\
\hline & compressor) \\
\hline Maximum engine speed & $1900 \mathrm{rev} / \mathrm{min}$ \\
\hline
\end{tabular}


Table 6.1 Table 2. Accuracies of Experimental Measurements

\begin{tabular}{lllll}
\hline Data Type & Make/Model & Type & Unit & Accuracy \\
\hline Temperature & Omega & K-type & ${ }^{\circ} \mathrm{C}$ & $\pm 0.75 \%$ of reading \\
Air mass flow & Flowmaxx & Sonic orifice & $\mathrm{kg} / \mathrm{h}$ & $\pm 0.1 \%$ of reading \\
Diesel mass flow & Micro Motion & Coriolis & $\mathrm{kg} / \mathrm{h}$ & $0.35 \%$ of reading \\
Methane mass flow & Micro Motion & Coriolis & $\mathrm{kg} / \mathrm{h}$ & $0.56 \%$ of reading \\
Smoke & AVL 415S & Filter & FSN & 0.001 of reading \\
$\mathrm{NO}_{\mathrm{x}}$ and NO & ESA EGAS 2M & CLD & $\mathrm{ppm}$ & $<1 \%$ of full scale \\
$\mathrm{THC}$ & ESA EGAS 2M & FID & $\mathrm{ppm}$ & $<0.5 \%$ of full scale \\
$\mathrm{CO}$ & ESA EGAS 2M & NDIR & $\%$ & $<1 \%$ of full scale \\
$\mathrm{CO}{ }_{2}$ & ESA EGAS 2M & NDIR & $\%$ & $<1 \%$ of full scale \\
Cylinder Pressure & Kistler 6052C & Piezoelectric & bar & \pm 0.005 of reading \\
Pressures(intake, & Setra Model 209 & Capacitance & psig & $\pm 0.25 \%$ of full scale \\
exhaust, etc.) & & & & \\
\hline
\end{tabular}


Table 3. Experimental Test Matrix

\begin{tabular}{lc}
\hline \hline Fixed Parameters & Varied Parameter \\
\hline \hline $\mathrm{PES}=80 \%, \mathrm{P}_{\text {rail }}=500 \mathrm{bar}, \mathrm{P}_{\text {in }}=1.5 \mathrm{bar}$ & $\mathrm{SOI}=280-355 \mathrm{CAD}$ \\
$\mathrm{PES}=80 \%, \mathrm{SOI}=310 \mathrm{CAD}, \mathrm{P}_{\text {in }}=1.5 \mathrm{bar}$ & Prail $=200-1300 \mathrm{bar}$ \\
$\mathrm{PES}=80 \%, \mathrm{SOI}=310 \mathrm{CAD}, \mathrm{P}_{\text {rail }}=500 \mathrm{bar}$ & $\mathrm{P}_{\text {in }}=1.1-1.8 \mathrm{bar}$ \\
\hline \hline
\end{tabular}




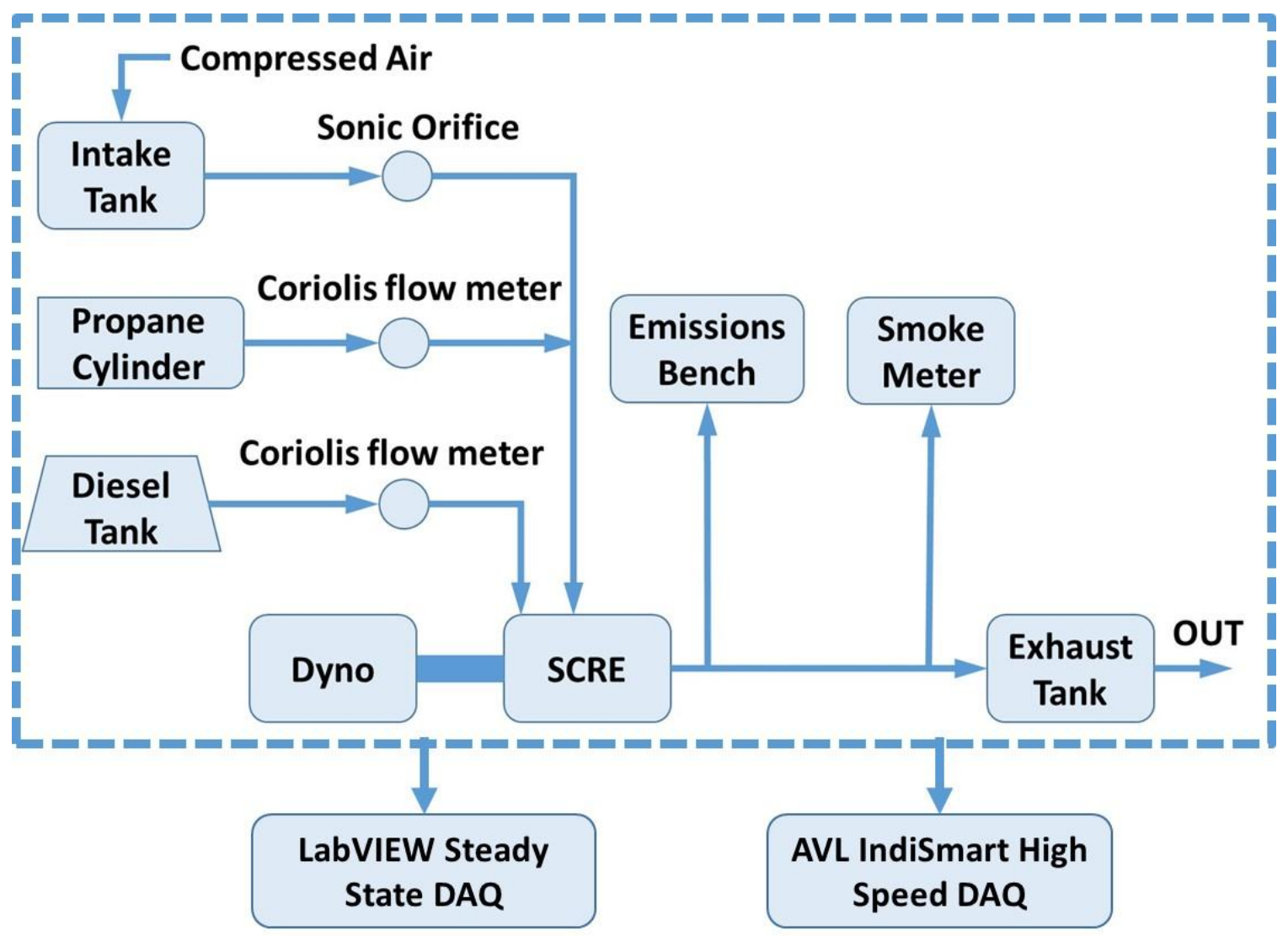

Figure 6.1 Figure 1. Experimental setup of the single cylinder research engine 


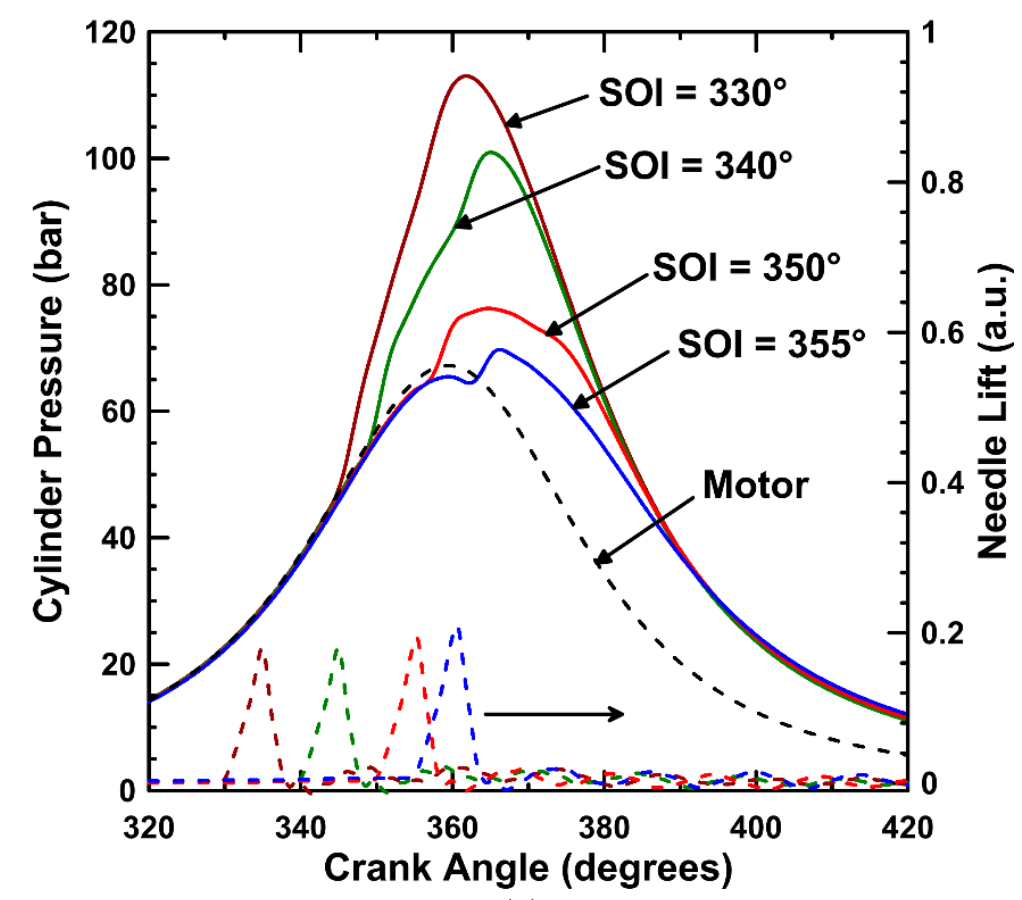

(a)

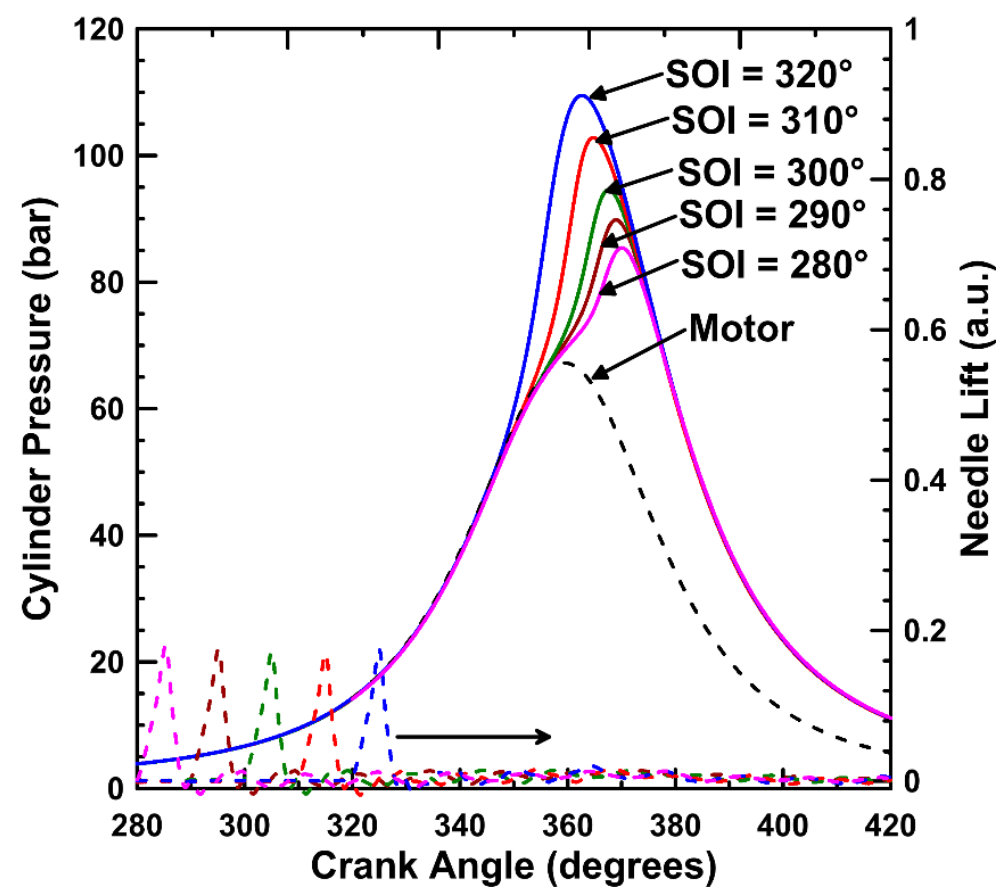

(b)

Figure 2. Cylinder pressure and needle lift histories at (a) retarded SOIs and (b) advanced SOIs with $P_{\text {rail }}=500$ bar, $P_{\text {in }}=1.5 \mathrm{bar}, 5.1 \mathrm{bar} I M E P, 80 \mathrm{PES}, N=1500 \mathrm{rev} / \mathrm{min}$ 


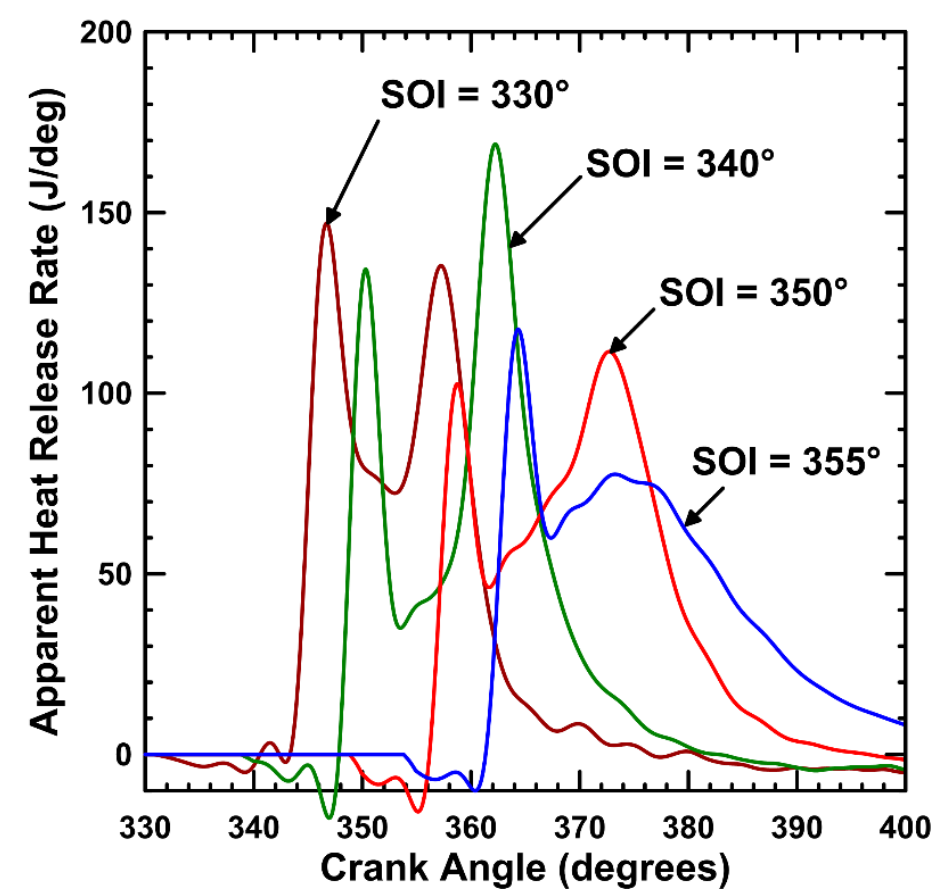

(a)

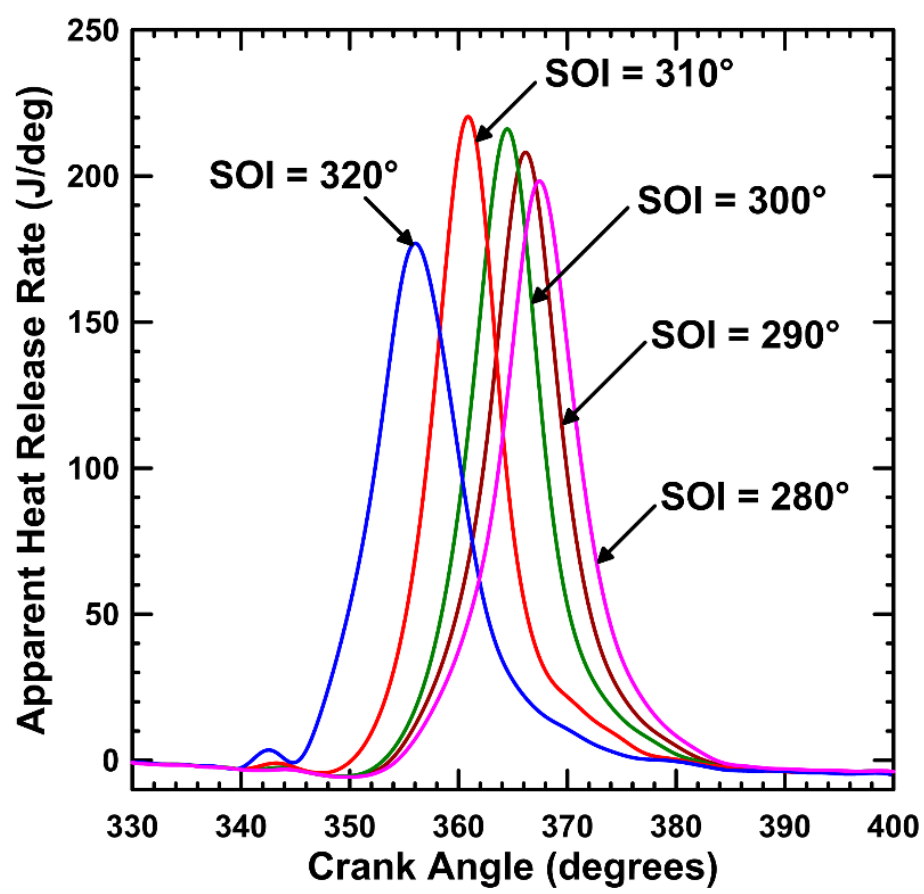

(b)

Figure 6.2 Figure 3. Apparent heat release rate histories at (a) retarded SOIs and $(b)$ advanced SOIs with $P_{\text {rail }}=500 \mathrm{bar}, P_{\text {in }}=1.5 \mathrm{bar}, 5.1 \mathrm{bar} I M E P, 80 \mathrm{PES}, N=1500 \mathrm{rev} / \mathrm{min}$ 


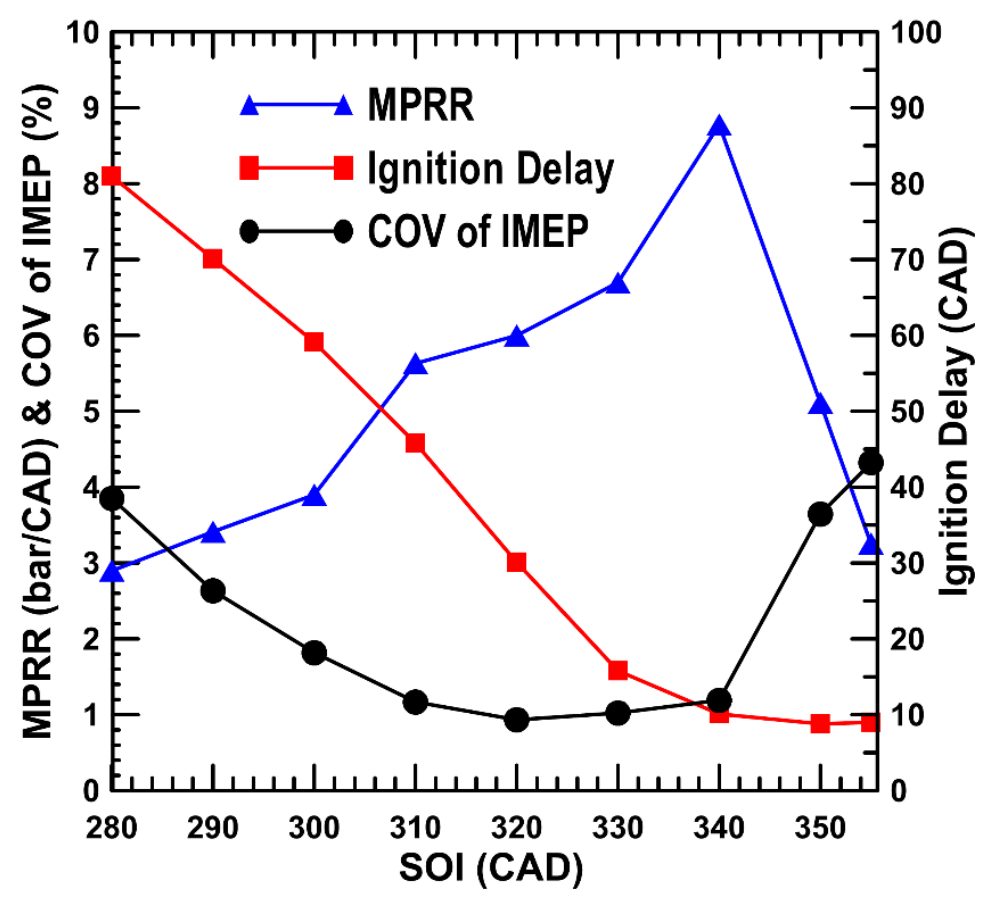

Figure 4. ID, MPRR, \& COV of IMEP vs. SOI, $P_{\text {rail }}=500 \mathrm{bar}, P_{\text {in }}=1.5 \mathrm{bar}$

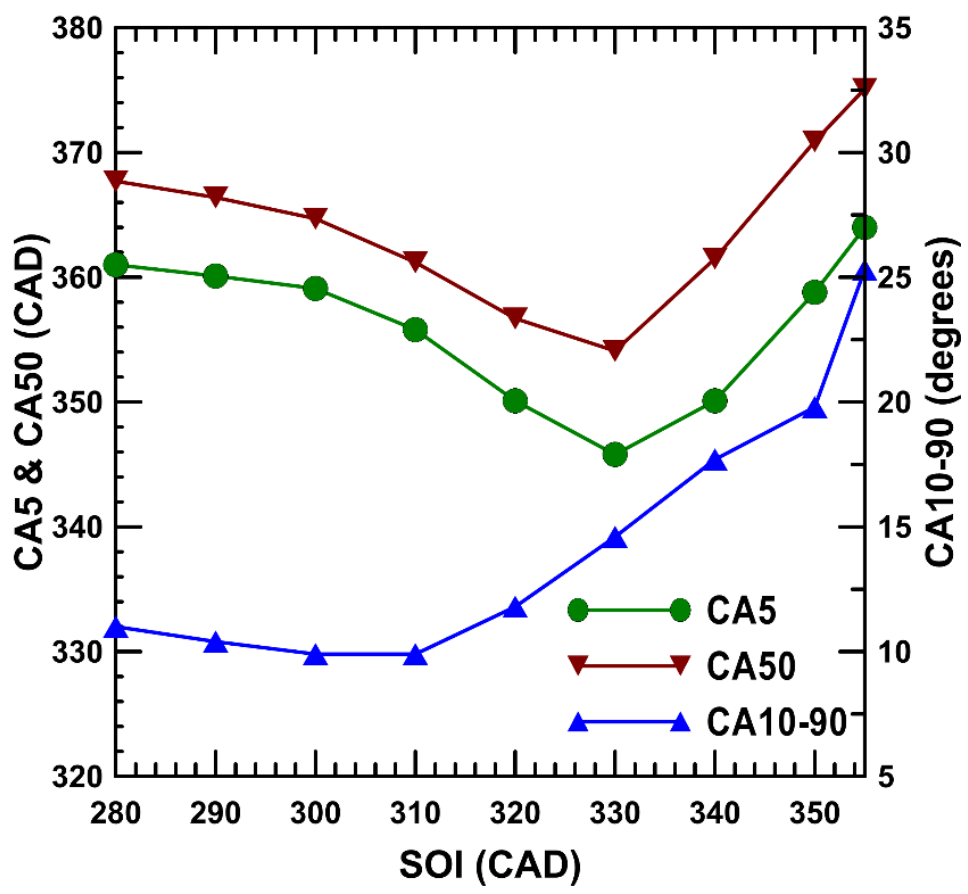

Figure 5. CA5, CA50, \& CA10-90 vs. SOI, $P_{\text {rail }}=500 \mathrm{bar}, P_{\text {in }}=1.5 \mathrm{bar}$ 


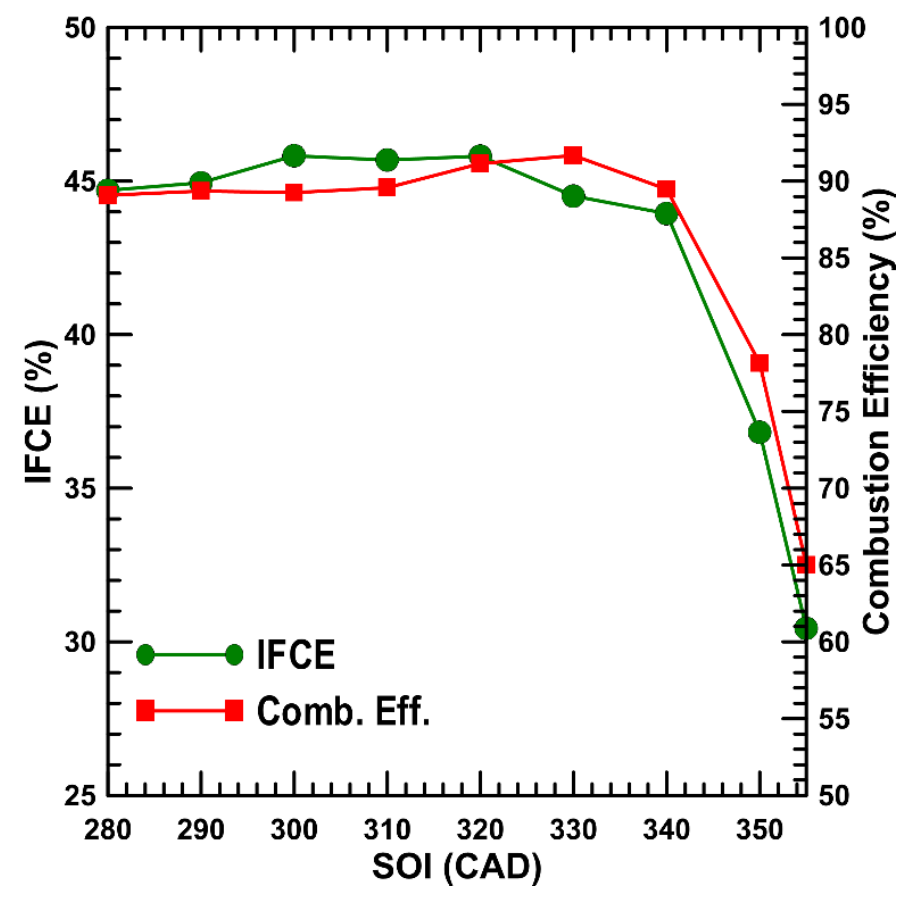

Figure 6. IFCE and $\eta_{\text {comb }}$ vs. SOI, $P_{\text {rail }}=500 \mathrm{bar}, P_{\text {in }}=1.5 \mathrm{bar}$

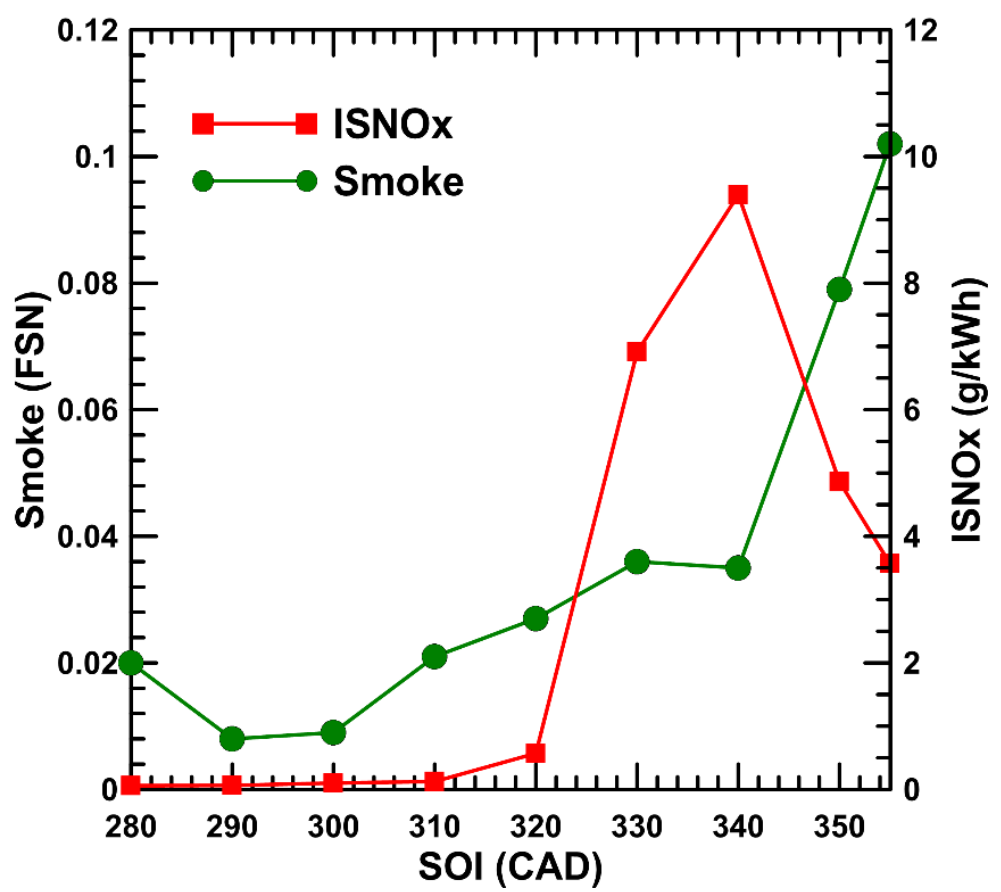

Figure 7. ISNOx and smoke vs. SOI, $P_{\text {rail }}=500 \mathrm{bar}, P_{\text {in }}=1.5 \mathrm{bar}$ 


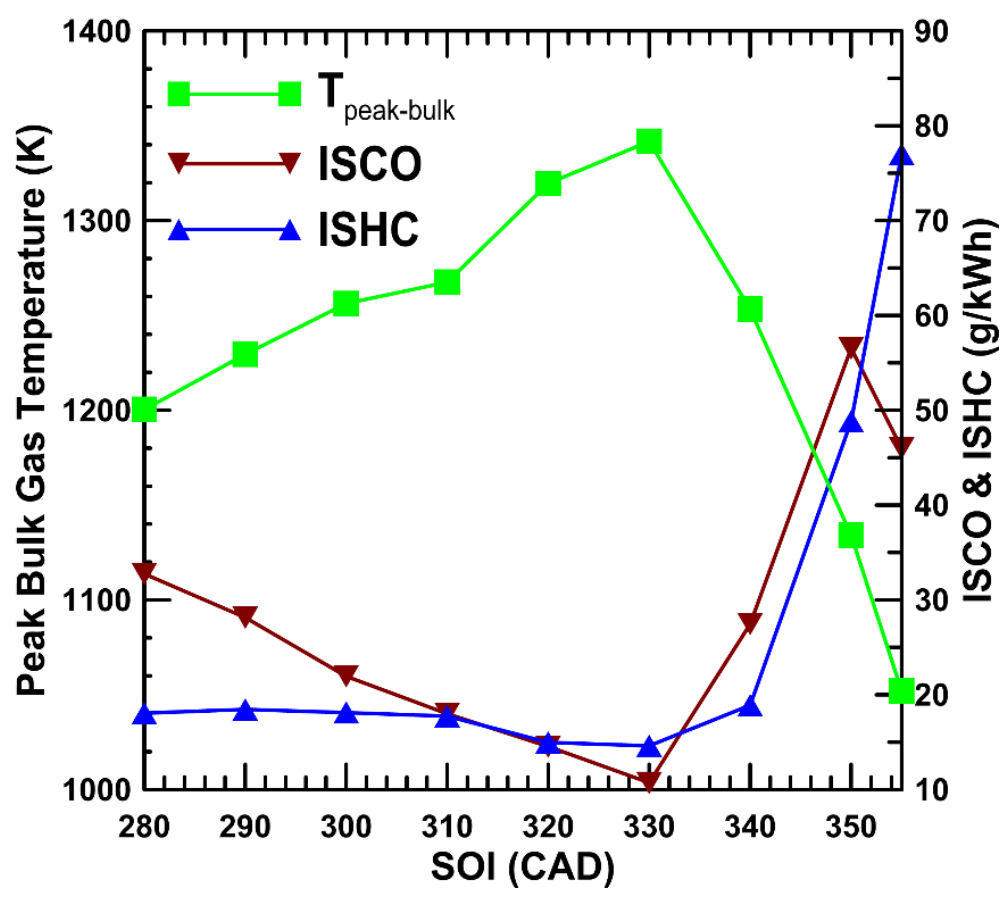

Figure 8. ISHC, ISCO, and peak bulk gas temperature vs. SOI, $P_{\text {rail }}=500$ bar, $P_{\text {in }}=1.5$ bar 


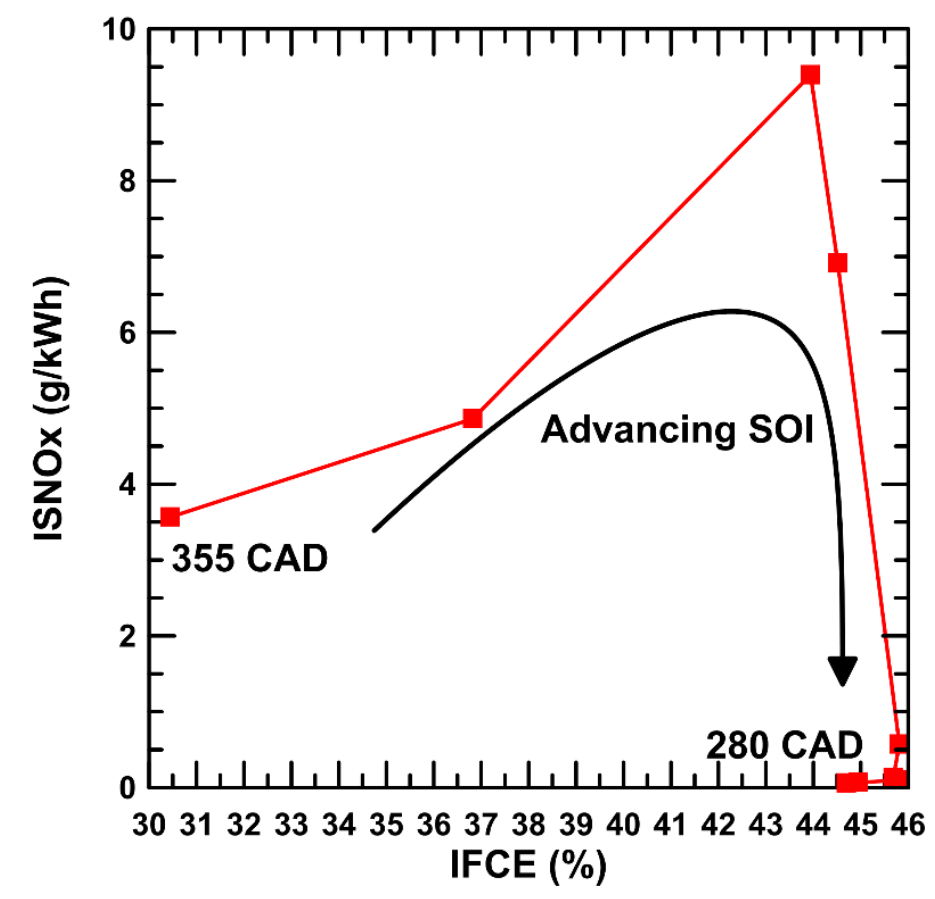

Figure 9. ISNOx vs. IFCE tradeoff at different SOIs

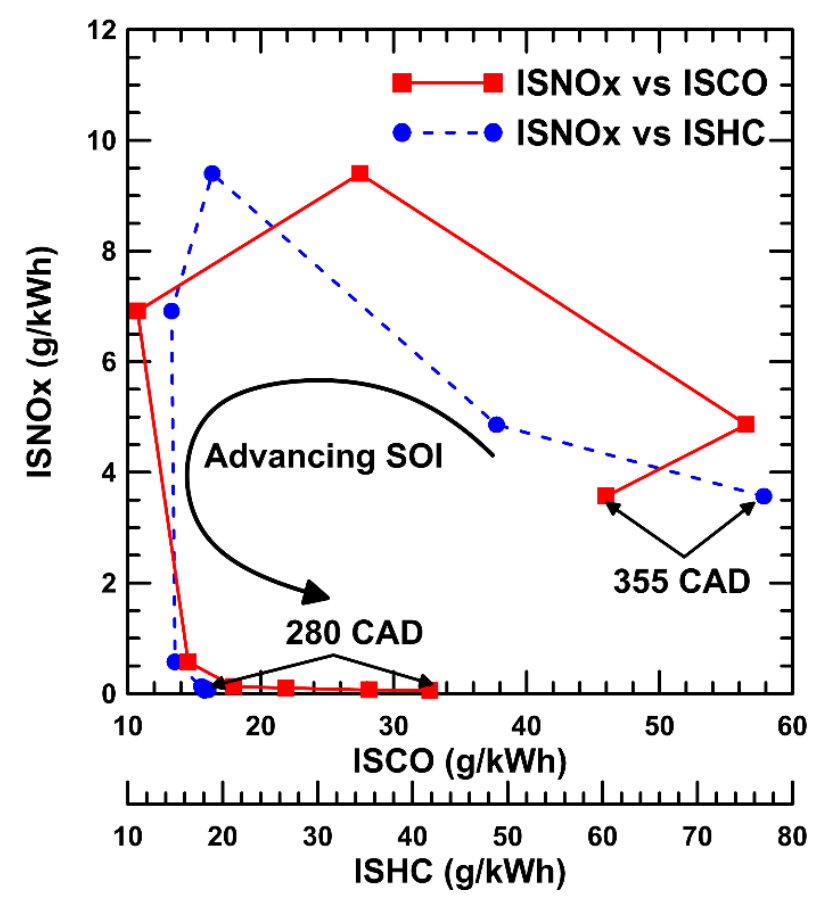

Figure 10. ISNOx vs. ISCO and ISNOx vs. ISHC tradeoffs at different SOIs 


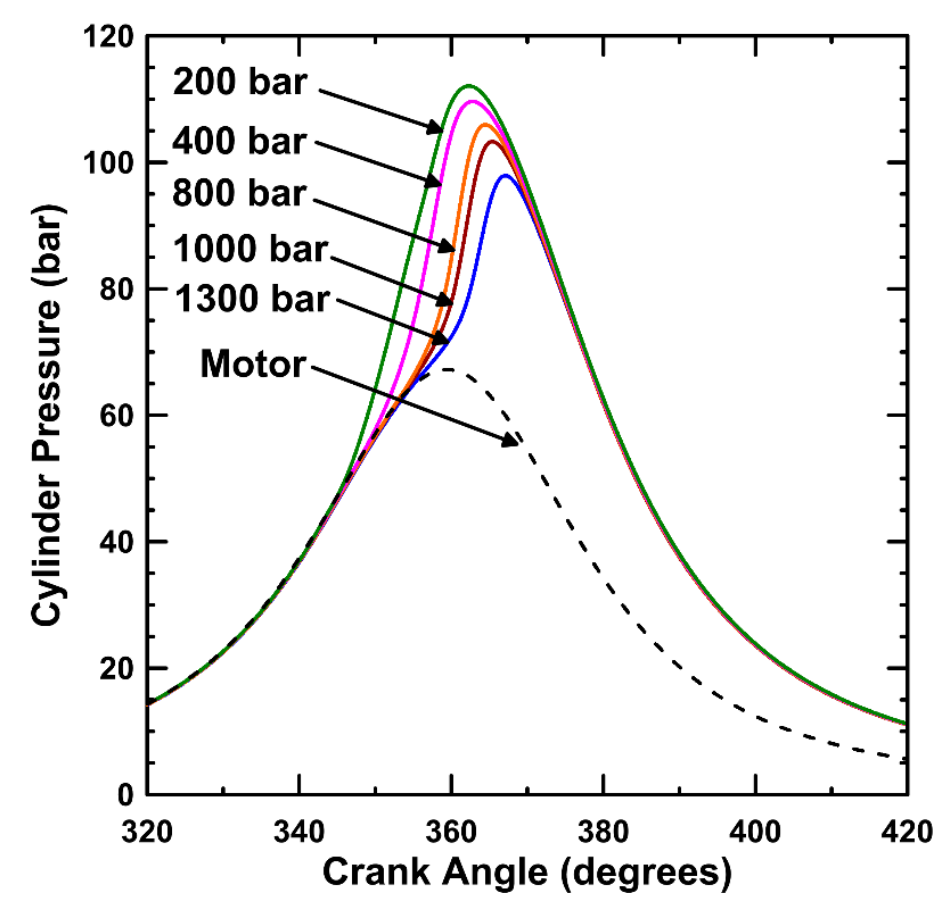

(a)

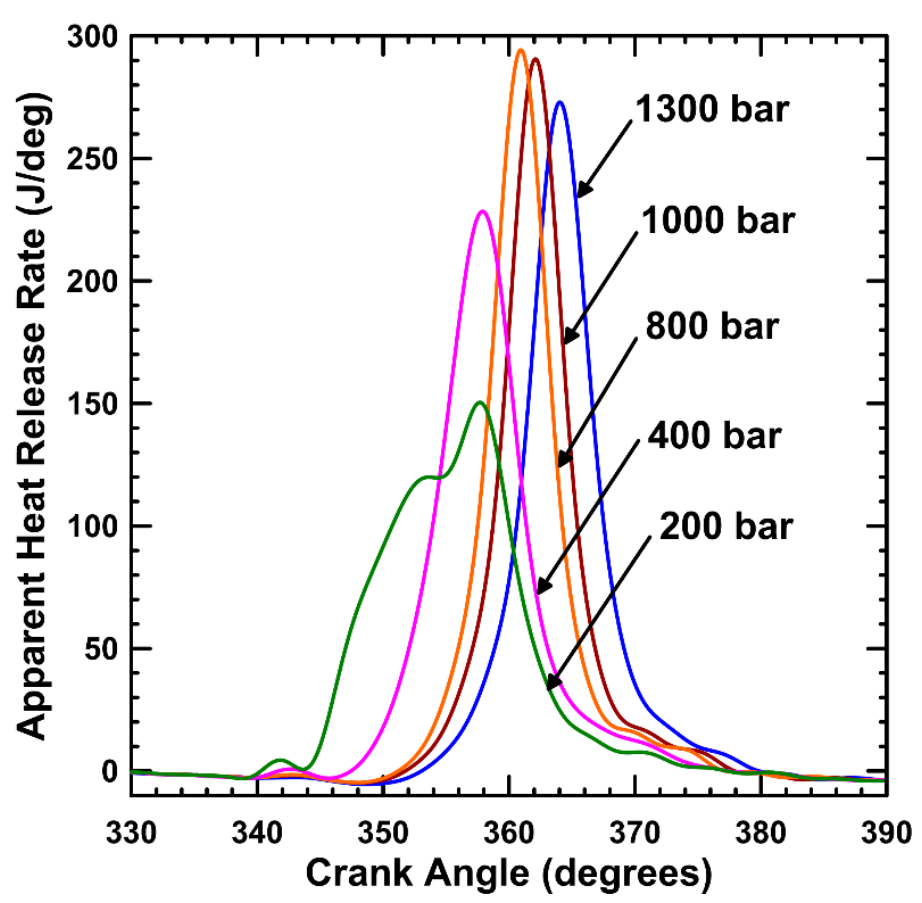

(b)

Figure 11. (a) Cylinder Pressure and (b) AHRR vs. $P_{\text {rail, }} S O I=310 C A D, P_{\text {in }}=1.5$ bar 


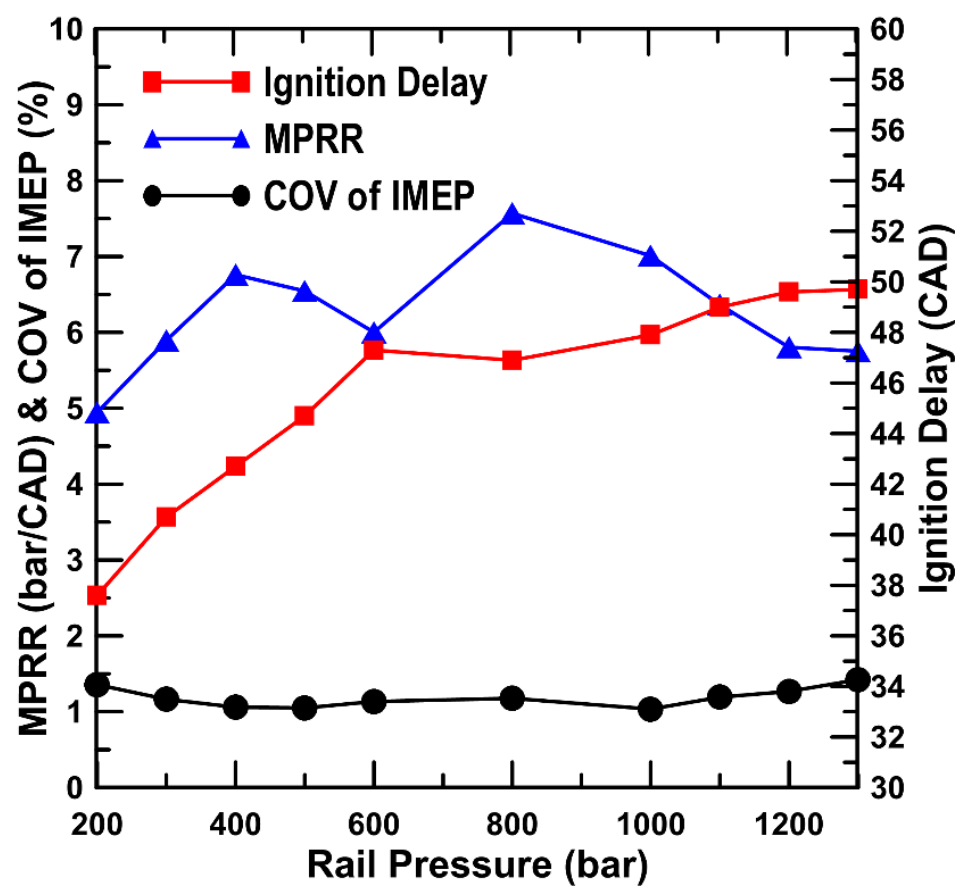

Figure 12. ID, MPRR, \& COV of IMEP vs. $P_{\text {rail }}, S O I=310 C A D, P_{\text {in }}=1.5 \mathrm{bar}$

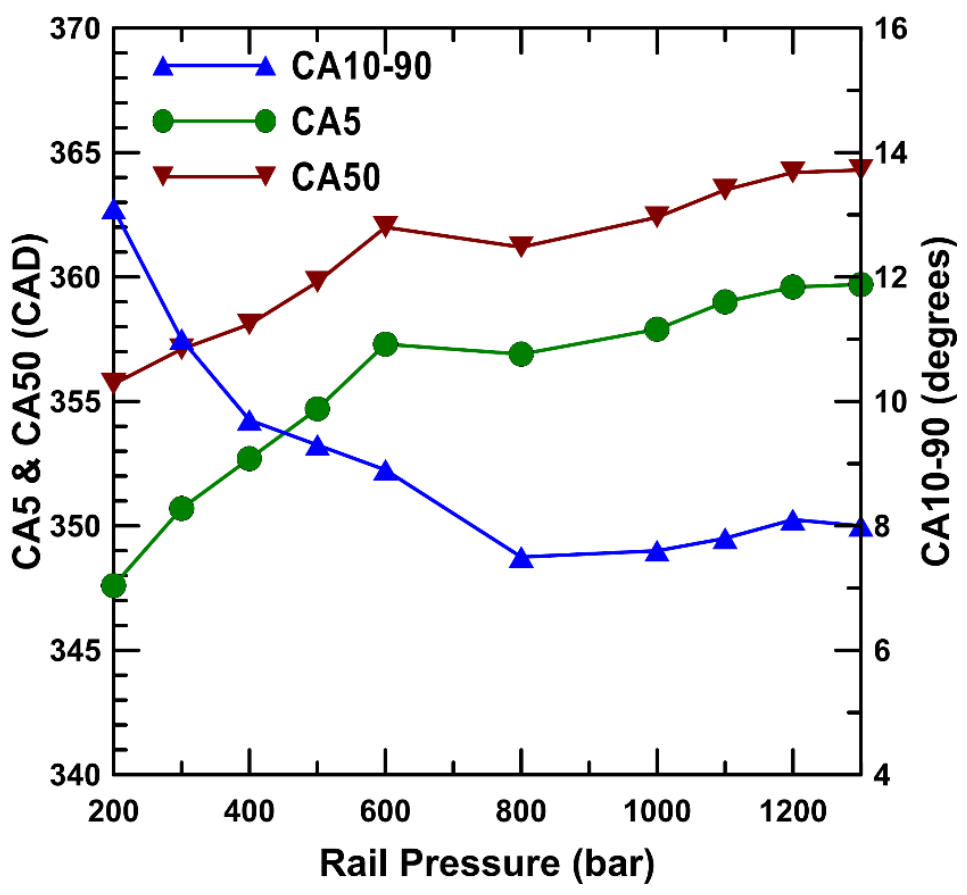

Figure 13. CA5, CA50, \& CA10-90 vs. $P_{\text {rail }}, S O I=310 C A D, P_{\text {in }}=1.5$ bar 


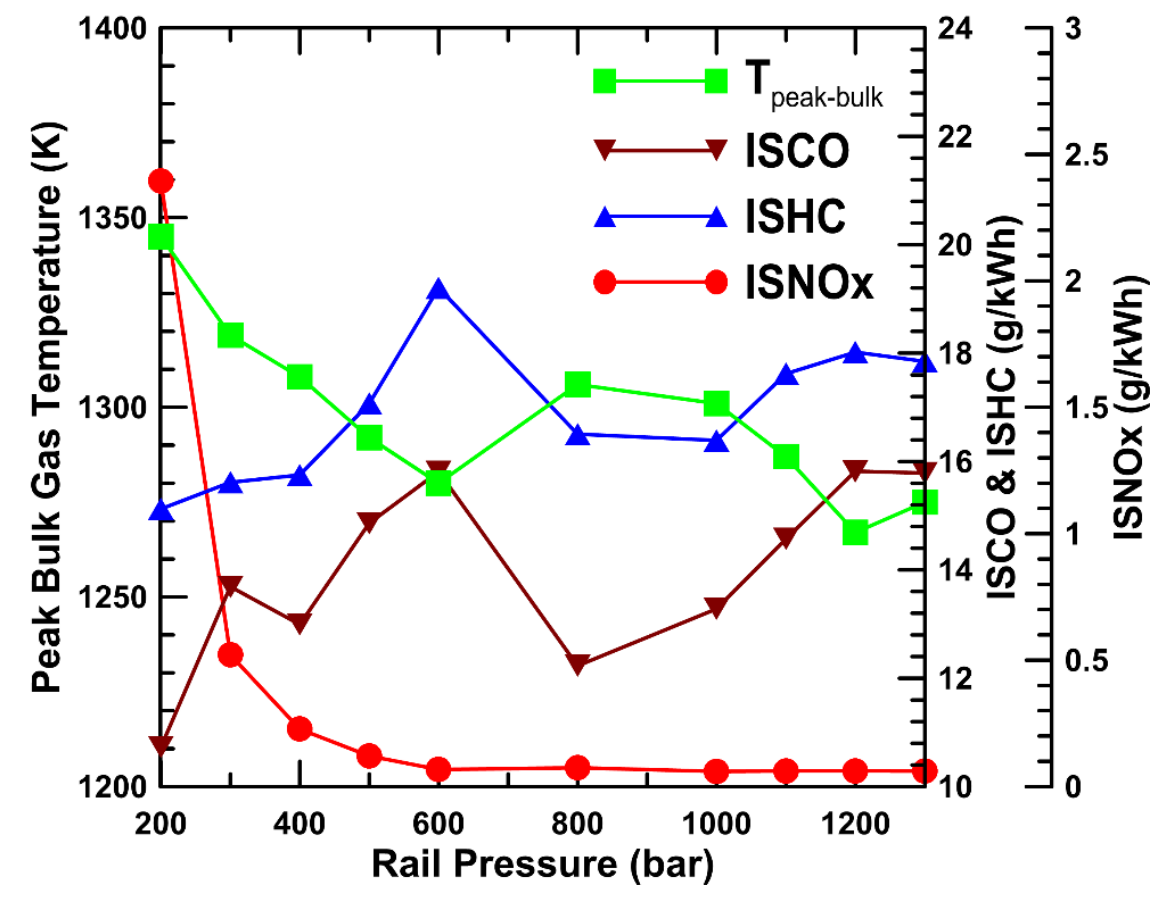

Figure 14. ISHC, ISCO, ISNOx, and peak bulk gas temperature vs. $P_{\text {rail }}, S O I=310 C A D$, $P_{\text {in }}=1.5 \mathrm{bar}$ 


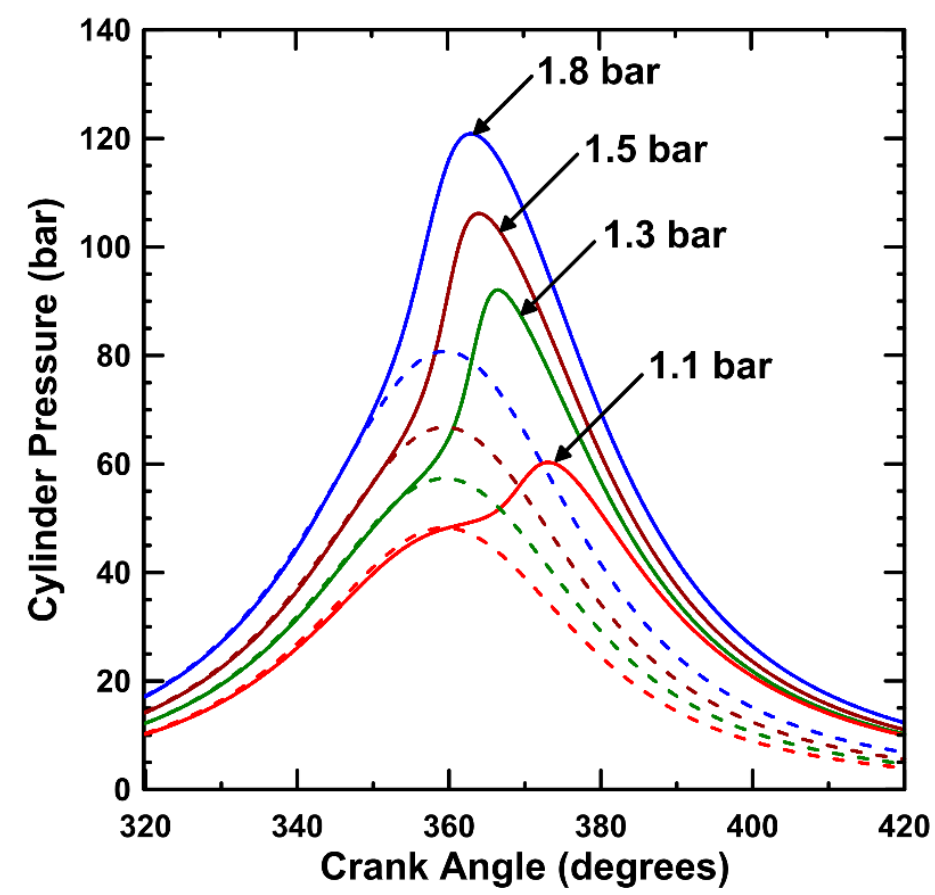

(a)

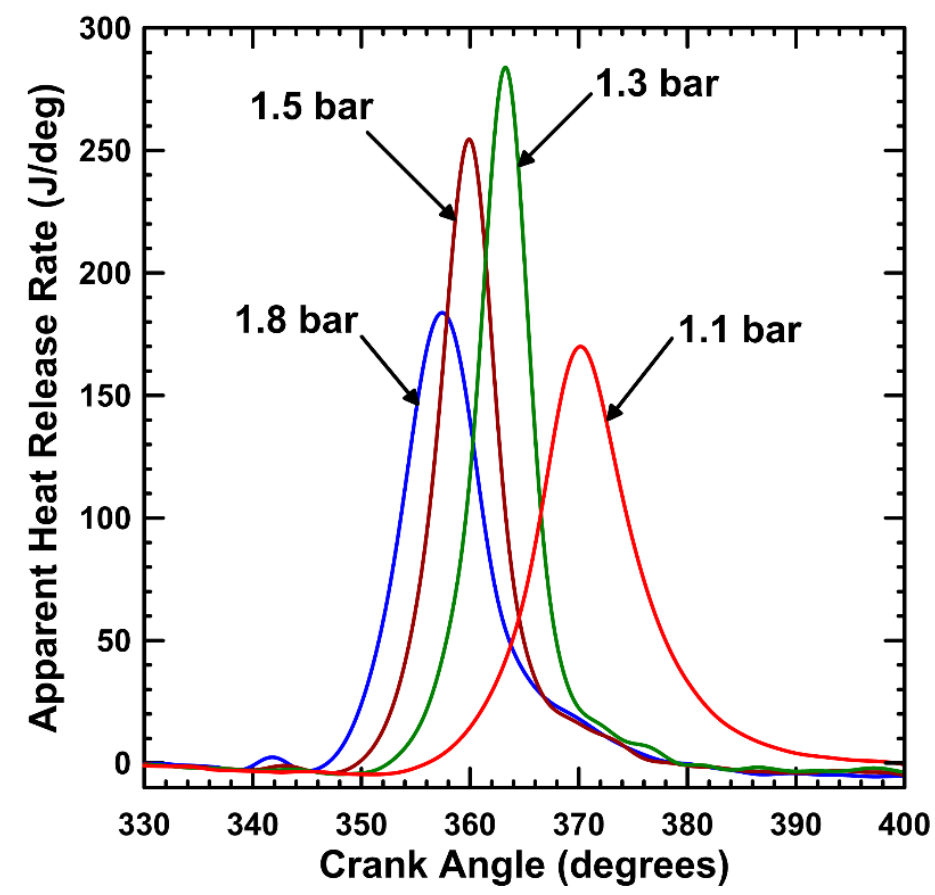

(b)

Figure 15. (a) Cylinder pressure and (b) AHRR vs. $P_{\text {in }}, S O I=310 C A D, P_{\text {rail }}=500$ bar 


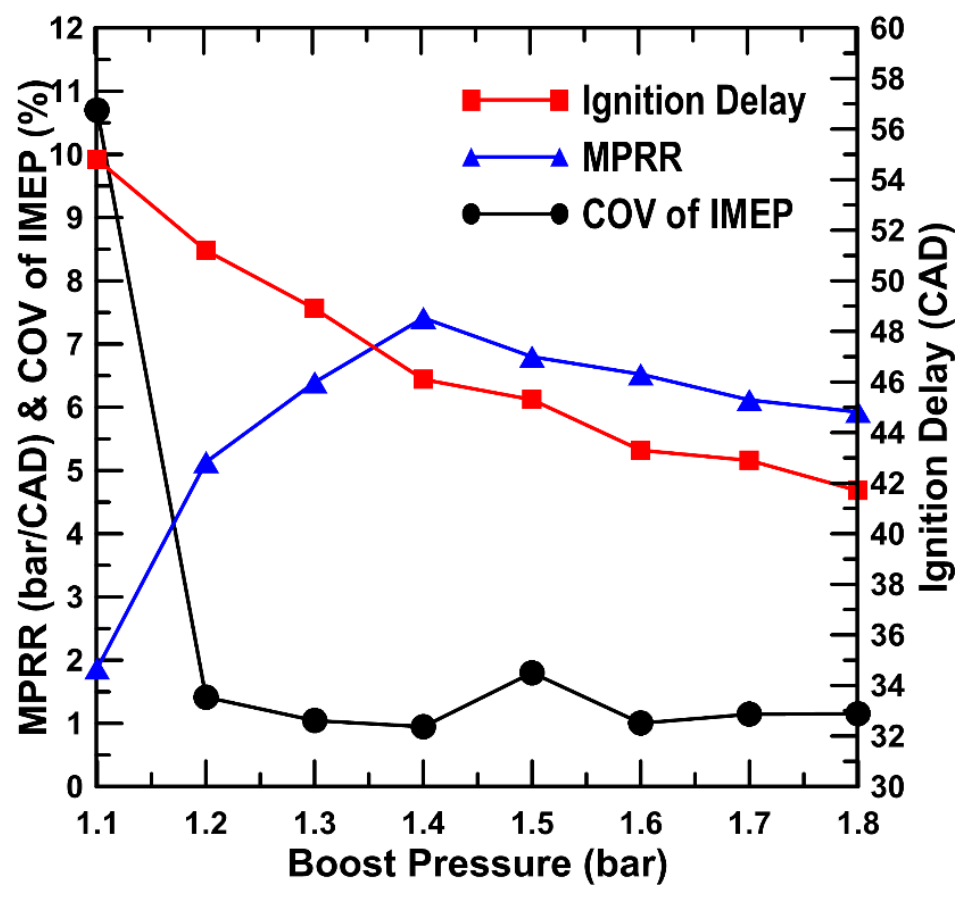

Figure 16. ID, MPRR, \& COV of IMEP vs. $P_{i n}, S O I=310 C A D, P_{\text {rail }}=500$ bar

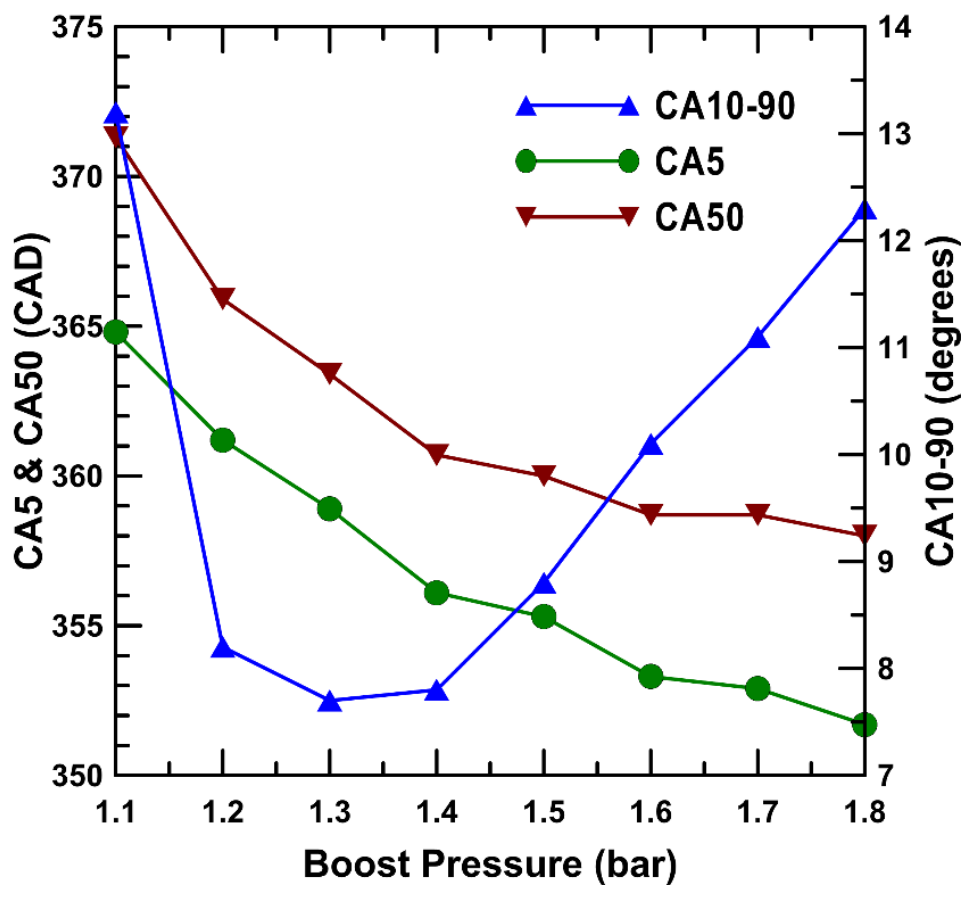

Figure 17. CA5, CA50, \& CA10-90 vs. $P_{\text {in }}, S O I=310 C A D, P_{\text {rail }}=500 \mathrm{bar}$ 


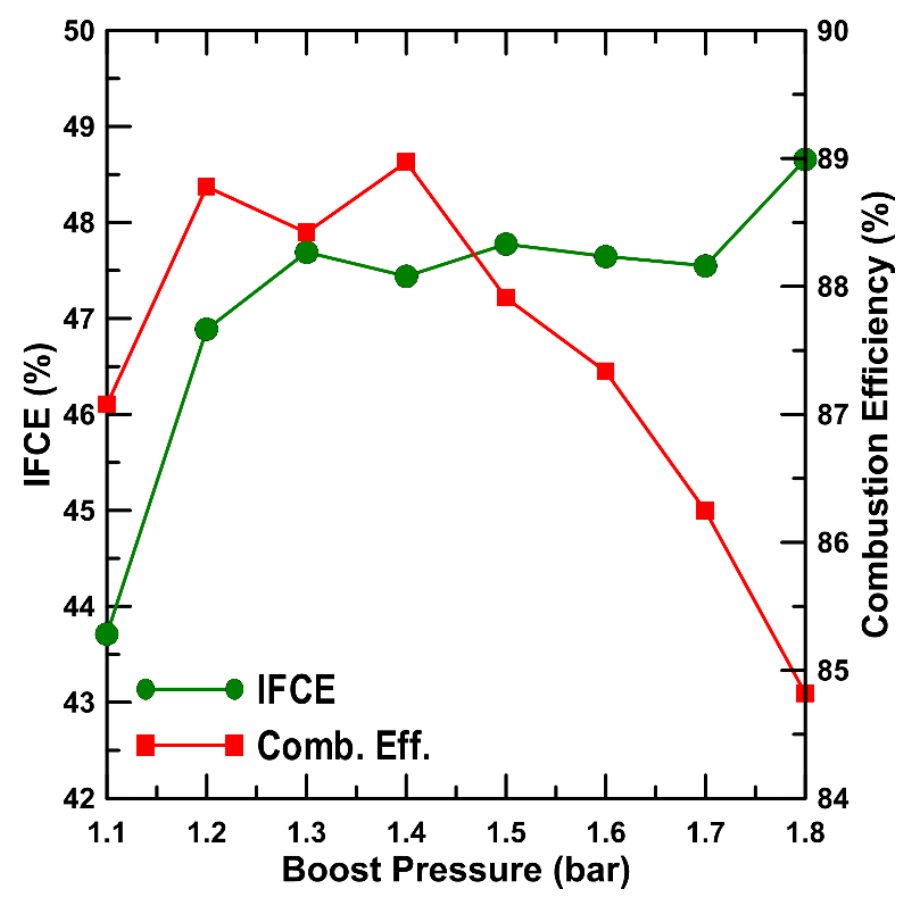

Figure 18. IFCE, $\eta_{\text {comb }}$ vs. $P_{\text {in }}, S O I=310 C A D, P_{\text {rail }}=500 \mathrm{bar}$

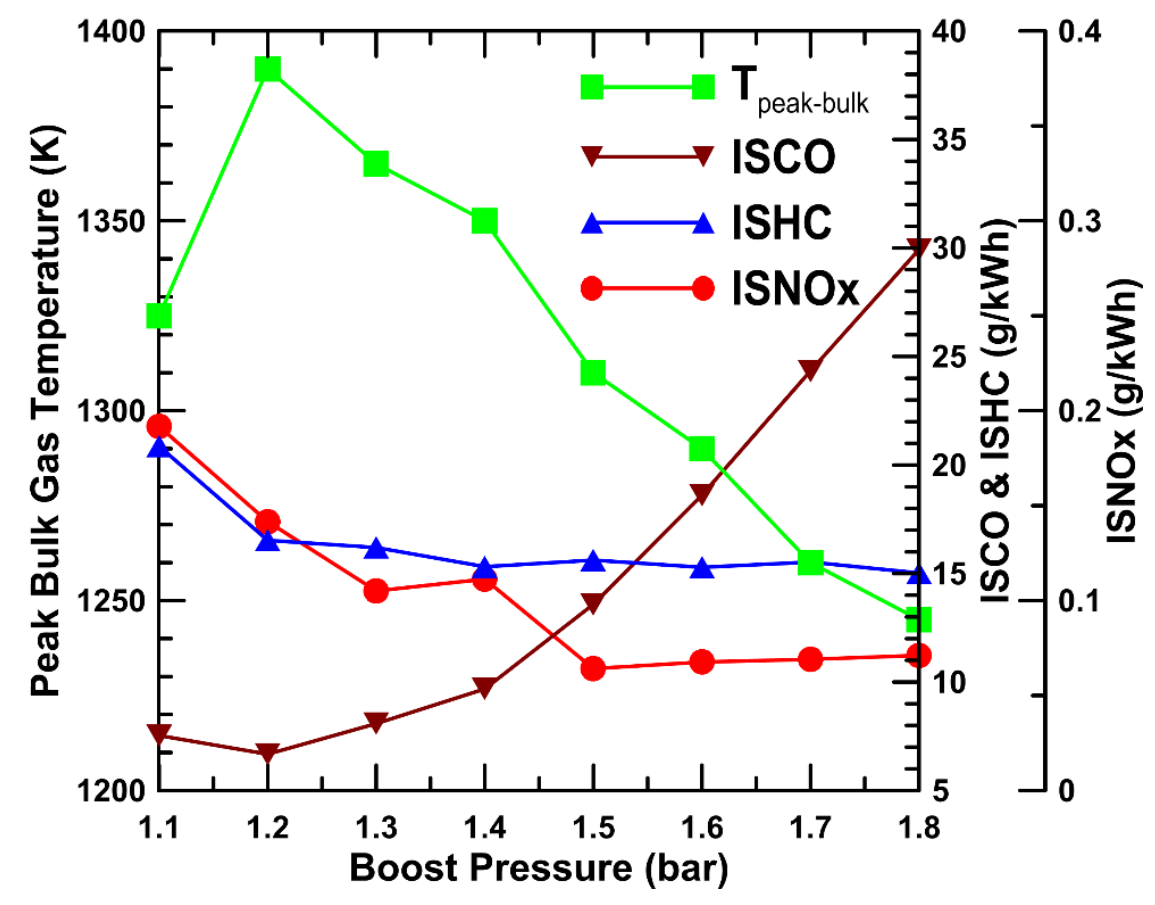

Figure 19. ISHC, ISCO, ISNOx, and peak bulk gas temperature vs. $P_{i n}, S O I=310 C A D$, $P_{\text {rail }}=500$ bar 